University of Nebraska - Lincoln DigitalCommons@University of Nebraska - Lincoln

2016

\title{
Semiochemicals in the Natural History of Southern Pine Beetle Dendroctonus frontalis Zimmermann and Their Role in Pest Management
}

B. T. Sullivan

USDA Forest Service

Follow this and additional works at: http://digitalcommons.unl.edu/usdafsfacpub

Part of the Forest Biology Commons, Forest Management Commons, Other Forestry and Forest $\underline{\text { Sciences Commons, and the Plant Sciences Commons }}$

Sullivan, B. T., "Semiochemicals in the Natural History of Southern Pine Beetle Dendroctonus frontalis Zimmermann and Their Role in Pest Management" (2016). USDA Forest Service / UNL Faculty Publications. 315.

http://digitalcommons.unl.edu/usdafsfacpub/315

This Article is brought to you for free and open access by the U.S. Department of Agriculture: Forest Service -- National Agroforestry Center at DigitalCommons@University of Nebraska - Lincoln. It has been accepted for inclusion in USDA Forest Service / UNL Faculty Publications by an authorized administrator of DigitalCommons@University of Nebraska - Lincoln. 


\section{Semiochemicals in the Natural History of Southern Pine Beetle Dendroctonus frontalis Zimmermann and Their Role in Pest Management}

\section{B.T. Sullivan}

USDA Forest Service, Southern Research Station, Pineville, LA, United States

\section{Contents}

1. Introduction

1.1 Bark Beetle Population Dynamics

1.2 Dendroctonus frontalis and Idiosyncratic Aspects of its Population Dynamics

2. Host Selection and Discrimination

2.1 The Need for Dual Strategies

2.2 Host Location by Pioneering D. frontalis

3. Concentration of Conspecifics for Mass Attack

3.1 The Aggregation Attractant

3.2 Frontalin

3.3 endo-Brevicomin

3.4 Host Monoterpenes

3.5 trans-Verbenol

3.6 Role of the Two Sexes in Mediating Mass Aggregation

4. Semiochemical Inhibition of Concentration (Antiaggregants)

4.1 Verbenone

4.2 Other Oxygenated Monoterpenes 156

4.3 Non-Monoterpene Aromatics 158

5. Attack Sequence 158

5.1 Establishment and Initiation of Spot Growth 158

5.2 Persistence and Termination of Spot Growth 162

6. Geographic Variation 163

7. Mate Finding and Selection 165

7.1 Aggregation vs Sex Pheromones 165

7.2 Pheromones in Reproductive Isolation 166 
8. Semiochemical Interactions with Arthropod Associates

8.1 Interspecific Pheromone Interactions with Other Bark Beetles 167

8.2 Exploitation of D. frontalis Pheromone by Predators and Parasitoids $\quad 169$

9. Exploitation of Semiochemistry in Management of D. frontalis 171

$\begin{array}{ll}\text { 9.1 Population Monitoring and Prediction } & 172\end{array}$

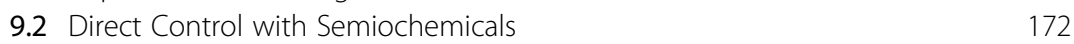

10. Concluding Remarks 178

$\begin{array}{ll}\text { References } & 179\end{array}$

\begin{abstract}
The southern pine beetle, Dendroctonus frontalis Zimmermann is generally considered to be one of the most significant biotic mortality agents of pines within North America, with a range stretching from New England to eastern Texas and from Arizona south to Nicaragua. As with other aggressive pine beetles, it relies on semiochemicals for coordinating the mass attacks necessary for colonization of healthy pines. Over the past 50 years its chemical ecology has received extensive study aimed at development of effective and practical semiochemical-based management strategies which might replace the destructive and costly techniques in practice. I review the literature on the chemical ecology of this insect with particular attention to the functional categorizations assigned to different semiochemicals and the data underlying these assignments. Additionally, I attempt to identify conflicts and knowledge gaps within current understanding of the chemical ecology of this insect that might represent a significant hindrance to progress in development of effective semiochemical-based management strategies.
\end{abstract}

\title{
1. INTRODUCTION
}

\subsection{Bark Beetle Population Dynamics}

Pine beetles, as do all bark beetles, feed and reproduce within the bark (particularly the phloem) of their host trees and most species, including the minority tree-killing or "aggressive" species, generally occur at low densities in the environment. They infest trees already killed or seriously weakened by other factors, such as disease, fire, windthrow, harvesting activities, climatic stresses, and damage from other species of insects. Under such conditions, their influences are considered to be generally positive relative to human concerns (eg, initiating the processes of breakdown of coarse woody debris and associated nutrient cycles; removal of unthrifty trees). These beetles normally have no impact on healthy pines, since such trees are able to generate a sufficient resin defensive response to kill or eject small numbers of beetles that may penetrate the bark and breach the resin ducts of the living host tissue. However, in the 
case of the aggressive, tree-killing bark beetle species, populations may reach outbreak densities sufficient for overwhelming host defences and permitting unimpeded colonization of bark tissue of entirely healthy, vigorous trees (Coulson, 1979). Tree death is assured by the girdling of the phloem tissue by the beetles' mining activities as well as the mass inoculation of weakly pathogenic fungi that the beetles carry into the host. Thus aggressive bark beetle species live double lives; persisting almost invisibly as scavengers in the environment when at low population densities but killing vast acreages of host trees as predators during outbreaks (Martinson et al., 2013; Raffa et al., 1993). The mass attacks required to kill a healthy tree are initiated, sustained, and potentially terminated through the beetles' pheromones (Byers, 1989b; Wood, 1982a), and semiochemicals are an essential mechanism underlying the epidemiology of these disturbance agents.

Host colonization by aggressive bark beetles has been divided into at least four stages: beetle dispersal from natal host material, selection of a host, population concentration on a host, and establishment within and commencement of reproduction by beetles in the host tissue (Raffa et al., 1993; Wood, 1982a). These categories apply to the spatial scale of a single tree; however, the most significant harm done by aggressive bark beetles occurs when mortality "spills-over" from one tree undergoing mass attack to those adjacent as these trees in turn become the new foci for attacks (Bentz et al., 1996; Powell et al., 1998; Renwick and Vité, 1970). The focus of beetle attacks moves typically from the initially attacked tree (possibly made susceptible to attack by fire/mechanical injury/disease-compromised defences) to the closest adjacent trees; these may be quite vigorous but nonetheless insufficiently defended from the overwhelming numbers of attacking beetles drawn-in by the pheromone of beetles attacking the original tree (Coulson, 1979; Coulson et al., 1985; Fargo et al., 1985; Schowalter et al., 1981). As this process is conducted from tree-to-tree, the ultimate result is a patch of contiguous killed hosts called an "infestation" or a "spot" (Ayres et al., 2011). It is through this pheromone-driven process called "switching" that aggressive pine beetles inflict most of their mortality on healthy trees and generate most of their economic and environmental impact (Bentz et al., 1996; Renwick and Vité, 1970; Schlyter et al., 1987a).

\subsection{Dendroctonus frontalis and Idiosyncratic Aspects of its Population Dynamics}

The southern pine beetle, Dendroctonus frontalis Zimmermann is generally considered the most economically important pest and biotic disturbance 
agent of pines (Pinus L.) within the southeastern United States (Clarke and Nowak, 2010; Pye et al., 2011; Tchakerian and Coulson, 2011), and ranges from Massachusetts to Texas, United States, and from Arizona, United States, south to Nicaragua. It will attack all species of pine within its range. It is a highly aggressive species and must kill its hosts in order to reproduce, and only occasionally is it found to attack prostrate hosts (Dixon and Osgood, 1961; Moser, 1987). As with other aggressive species of bark beetle, its status as a major pest arises from its capacity to kill healthy trees and be the primary agent of tree mortality (Wood, 1982b).

Dendroctonus frontalis can have five to seven generations per year that last from 26 to 54 days (Birt, 2011; Fronk, 1947; Hain et al., 2011) in the southern part of its range, and there is much overlap of generations particularly as summer progresses (Franklin, 1970). Dendroctonus frontalis is distinctive from most other aggressive species of Dendroctonus pine beetles in North America in that the growth of individual spots can continue for months and cover hundreds of hectares during a single season if unchecked (Clarke and Billings, 2003; Schowalter et al., 1981). Because of the short generation time of this species, it is possible for mass attacked and therefore aggregation pheromone-producing trees to still be present within a spot when the first generation of brood emerge (Franklin, 1970). It has been shown that emerging brood beetles tend to remain concentrated in the area where they emerge if a source of aggregation pheromone is present; otherwise they disperse into the surrounding forest (Cronin et al., 1999; Gara, 1967). Thus a high proportion of these emerging brood fly to the nearby mass-attacked trees [typically less than $50 \mathrm{~m}$ away (Ayres et al., 2011)] and continue the process of mass attack and host switching initiated by their parents (Franklin, 1970). Unlike many bark beetles (Bennett and Borden, 1971; Byers, 1989b), D. frontalis requires little if any flight exercise before they are responsive to their aggregation pheromone (Andryszak et al., 1982), a demand that would otherwise promote dispersal from an infestation. This behaviour starts a cycle of brood emergence and participation in the mass attack and switching at the growing infestation's "head" (ie, the zone of the infestation where mass attack is occurring and concentrations of aggregation pheromones are highest). In general, $D$. frontalis infestations can continue to grow by this process as long as suitable host pines are close enough to the infestation's head to allow switching to occur and there is sufficient replacement of parent beetles by their brood or beetles recruited from outside the infestation (Ayres et al., 2011). The infestations tend to grow in a single, predominantly downwind, direction (Coster et al., 1978). Because 
persisting infestation growth is a trait not shared with other major pine beetle pests in North America, procedures for direct control of beetle damage are also quite different for $D$. frontalis, with suppression of infestation growth being the primary approach taken (Clarke, 2001).

In this chapter I will review the chemical ecology of $D$. frontalis, a subject that has received intensive research interest for over 50 years. Southern pine beetle was the first bark beetle species for which a multifunction, multicomponent pheromone system was described (Renwick and Vité, 1969), and it generated the first hypotheses proposed for mediation of bark beetle host colonization by both aggregation and antiaggregation pheromones.

\section{HOST SELECTION AND DISCRIMINATION}

\subsection{The Need for Dual Strategies}

All aggressive bark beetle species must be adept at two very distinct host location and colonization strategies if they are to endure their characteristically extreme population cycles. At low numbers, they must be able to locate hosts that are sufficiently weak that colonization does not first require a conspecific mass attack to deplete host defences; under these circumstances, the chances of encountering conspecific pheromone that might guide them to a host undergoing colonization are relatively low and insufficient numbers of beetles would be "in range" to detect the pheromone signal of pioneers. During outbreaks, dispersing beetles are readily available in the environment to respond to aggregation pheromone and thereby reduce the risk posed to any courageous pioneer beetles that choose to attack a tree that they would not be able to colonize alone. Once an infestation is established, the plumes of pheromone generated from the mass-attacked trees are beacons that can be used by dispersing beetles to locate the abundant and high quality hosts being made available for colonization due to the elevated local densities of beetles. However, under both high and low populations, there must be pioneers that, without the aid of pheromones, can locate hosts that they can either colonize directly or utilize as points for initiating a mass attack that will render the tree suitable for their colonization.

\subsection{Host Location by Pioneering $D$. frontalis}

Some literature on aggressive bark beetles has been devoted to the mechanisms of host location/selection utilized by the first, pioneer bark beetles that 
arrive on a suitable host pine and initiate the process of mate attraction and/ or concentration of conspecifics through release of pheromones. This cycle (ie, landing, pheromone release, and attraction of conspecifics that themselves make a quantitative contribution to the pheromone plume) is a positive-feedback loop that drives mass attacks and results in overwhelming of host defences and host colonization. Once a host is selected by a pioneer individual-by whatever means - pheromones produced by the pioneer presumably could be sufficient as long-range attraction cues for initiating this loop. In some beetle species it is evident that host-produced (or "primary") host location/discrimination cues can be sensed by the pioneer beetles at a distance (Gara et al., 1984; Heikkenen, 1977; Miller et al., 1986; Moeck and Simmons, 1991). Some bark beetles, including major tree killers, have been shown to be attracted to olfactory cues associated with naturally or artificially compromised hosts (Gara et al., 1984; Macias-Samano et al., 1998; Moeck and Simmons, 1991; Pureswaran and Borden, 2005). Alternatively, beetles may select a host by means of close-range olfactory, gustatory, or other contact cues following random landing on the bark surface. These beetles land presumably in response to the host's dark vertical silhouette and evaluate each tree before attempting to initiate a mine; they resume flight if the tree is found to be unsuitable (Byers, 1996; Hynum and Berryman, 1980; Moeck, 1978; Moeck et al., 1981; Saint-Germain et al., 2007). Evidence that beetles follow this "random landing" strategy include that (1) in some instances landing frequency by dispersing beetles on potential host trees is uncorrelated to subsequent attacks or is not stimulated by artificial treatments inducing host susceptibility (Hynum and Berryman, 1980; Moeck et al., 1981; Raffa and Berryman, 1980), and (2) models which indicate that, although long-range identification of suitable host trees by primary cues may be a more efficient host selection strategy, random landing is a sufficient means for host location by pioneers (Byers, 1996; Gries et al., 1989). Under the random landing hypothesis, any long-range selection of hosts is due to the aggregation pheromone (potentially synergized by otherwise unattractive host-produced compounds) released by the pioneers and then augmented by subsequent beetles that join them in the attack.

There is no compelling evidence that pioneering $D$. frontalis initially locate suitable hosts by primary attraction. Unlike many of their nonaggressive associates, $D$. frontalis are not attracted to whole or distilled (ie, turpentine) resin of host pines in the absence of beetle pheromones (Billings, 1985; Kinzer et al., 1969; Payne et al., 1978a; Sullivan et al., 2007b; Vité and Renwick, 1968) and apparently not to pine logs screened 
from beetle attacks (Svihra, 1982). However, $\alpha$-pinene alone attracted both sexes (McCarty et al., 1980) or male (Niño-Domínguez et al., 2015b) D. frontalis in ambulatory laboratory olfactometers, suggesting that the compound alone may affect activity of beetles post-landing if not in flight. Pines located at points distant from active infestations (and thus free from the influence of semiochemicals from attacked trees) have been weakened artificially and this resulted in their nearly simultaneous colonization by $D$. frontalis together with associated bark beetles (Heikkenen, 1977; Rykiel et al., 1988). Tree disturbance methods included severing a pine while maintaining its vertical orientation (Heikkenen, 1977), detonating a blast cord wrapped around the bole to imitate the physical damage produced by a lightning strike (Coulson et al., 1986), or mechanical removal of a $15 \mathrm{~cm}$-wide strip of bark from crown to base (Payne, 1986). However, these tree boles were not enclosed by screen to prevent bark beetle attacks. Hence it cannot be ruled out that randomly landing $D$. frontalis attacking the artificially susceptible trees could have subsequently released pheromone thereby initiating secondary attraction, or that $D$. frontalis were responding to secondary attractants of other insects.

Lightning strikes appear to be the most common disturbance that weakens individual trees sufficiently to allow colonization by small numbers of $D$. frontalis, and $10 \%$ to $75 \%$ of $D$. frontalis infestations have their origins in a lightning-struck tree (Coulson et al., 1983; Lovelady et al., 1991). Susceptibility is due at least in part to a temporary reduction of the struck tree's constitutive defences (Blanche et al., 1985; Hodges and Pickard, 1971). It has been noted that the distribution of lightning strikes in both space and time puts them within the dispersal range of southern pine beetles (Kinn, 1986; Turchin and Thoeny, 1993). The resulting reliability of lightningstruck pines assures the continuous availability of host material for D. frontalis within which low-level populations can be sustained or build to levels capable of initiating an infestation (Coulson et al., 1999; Lovelady et al., 1991; Rykiel et al., 1988). The speed and dependability with which lightning-struck trees can be attacked by $D$. frontalis and associated bark beetles have led to speculation about the existence of a primary attractant generated by the strike (Hodges and Pickard, 1971). However, preliminary coupled gas chromatography-electroantennographic detection (GC-EAD) analyses of $D$. frontalis responses to aeration samples of recently struck pines (Fig. 1) have not indicated the presence of olfactory stimulants other than major volatile constituents of $P$. taeda resin, which have not been shown to be attractive to $D$. frontalis in the absence of beetle-produced 


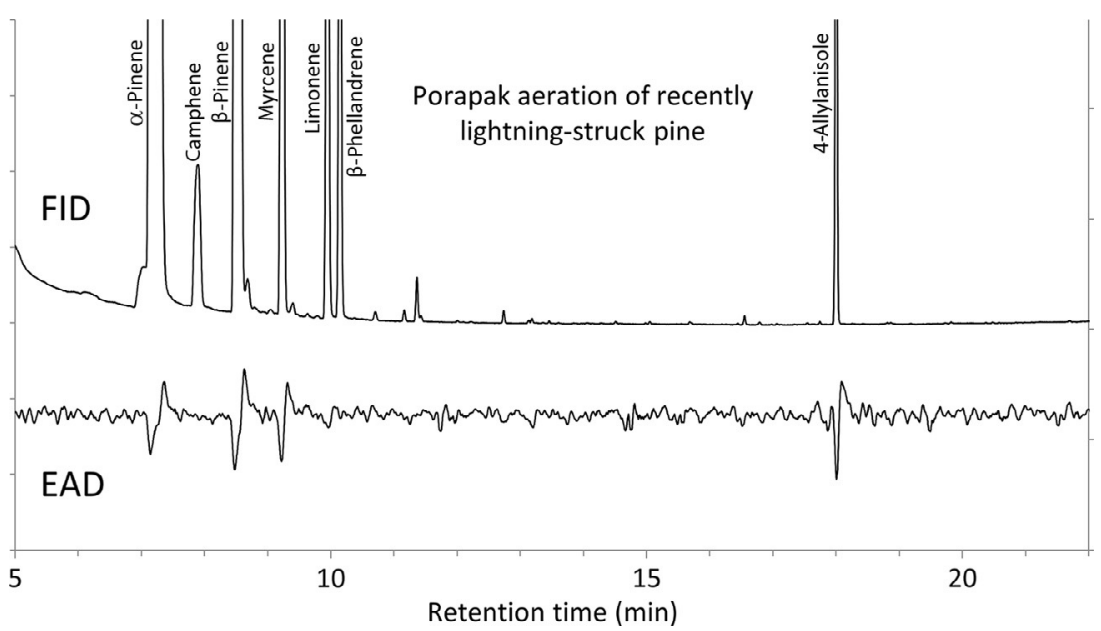

Fig. 1 Coupled gas chromatography-electroantennographic detection (GC-EAD) analysis of two female $D$. frontalis antennal clubs (GC-EAD analyses summed digitally) in response to a concentrated pentane extract of a $3 \mathrm{~h}$ Porapak $\mathrm{Q}$ (Waters; Milford, Massachusetts, United States) sampling of air from the bole of a $P$. taeda that had been recently (within days) struck by lightning. A $1 \mathrm{~m}$ length of the bole including areas with sapwood exposed by the strike had been enclosed in PTFE sheeting to concentrate odours at the air intake of the adsorbent cartridge. The tree had not been attacked by subcortical insects except for a single $D$. terebrans entrance at the soil-line, and I sampled $>1 \mathrm{~m}$ above this attack. The GC-EAD apparatus and antennal preparation methods were as in Sullivan (2005). Antennograms courtesy of Dr. William Shepherd, USDA Forest Service, Southern Research Station.

compounds (Billings, 1985; Kinzer et al., 1969; Payne et al., 1978a; Sullivan et al., 2007b). The aforementioned experiments with blast cord were intended to induce host suitability and $D$. frontalis attacks by duplicating, at least in part, the effects of a lightning strike on a host tree (Miller, 1983). Payne (1986) hypothesized that the very large release of resin odours from a lightning-caused wound at the approximate height of preferred flight for $D$. frontalis (ie, mid-bole) might generate close-range arrestment and thereby provide a short-range primary semiochemical cue for $D$. frontalis otherwise searching randomly.

However, lightning-struck or otherwise disturbed trees may be rapidly attacked by a variety of bark beetle species within the southern pine bark beetle guild and not merely D. frontalis (Anderson and Anderson, 1968; Coulson et al., 1985; Flamm et al., 1993). At least two of these species [Ips grandicollis (Eichhoff) and Dendroctonus terebrans (Olivier)], unlike 
D. frontalis, unquestionably respond to primary attractants including compounds (eg, host resin monoterpenes) (Erbilgin and Raffa, 2000; Fatzinger, 1985; Fatzinger et al., 1987; Miller and Rabaglia, 2009; Phillips et al., 1988; Siegfried et al., 1986; Werner, 1972) that are released from the exposed sapwood and phloem tissue of lightning-struck pines. Both species release pheromones post-landing, and it is a conceivable strategy for $D$. frontalis to rely on these other species to locate lightning-struck trees and to then exploit the pheromones of these species as kairomones in locating breeding material. Such "third-party" secondary attraction seems unlikely in the case of $I$. grandicollis since $D$. frontalis are not attracted to logs infested with Ips grandicollis or Ips pheromone components (Birch et al., 1980; Svihra et al., 1980). However, as suggested by Hodges and Pickard (1971), D. terebrans could play a role in attracting D. frontalis to trees struck by lightning or receiving other types of injury. Dendroctonus terebrans is typically the first bark beetle species to arrive on a lightning-struck tree (Hodges and Pickard, 1971), whereas attacking D. terebrans pairs generate all components of the D. frontalis aggregation attractant (Payne et al., 1987; Phillips et al., 1989): frontalin and trans-verbenol (by females), both endo- and exo-isomers of brevicomin (by males), and resin odors from the damaged host tissue. Thus, as suggested by Payne et al. (1987), a kairomonal response by $D$. frontalis to trees attacked by $D$. terebrans could assist the former in locating lightning-struck host trees. Dendroctonus terebrans restrict their attacks to the lower 1-2 $\mathrm{m}$ of the host bole hence they compete minimally for phloem resources with $D$. frontalis (Thatcher, 1960). As an additional conceivable benefit to $D$. frontalis, $D$. terebrans attacks might also weaken the tree or in some other way increase its susceptibility to $D$. frontalis colonization.

\section{CONCENTRATION OF CONSPECIFICS FOR MASS} ATTACK

A female southern pine beetle that has selected a host (which she has identified through the presence of conspecific pheromones or its own evaluation of host quality upon contact and inspection) will release pheromones with at least two potential functions: attracting a mate and, if the host is producing resistance, attracting conspecifics of both sexes to overcome host defences. As with all bark beetles, pheromone components are accumulated in the hindgut and released from the anus. 


\subsection{The Aggregation Attractant}

The aggregation attractant for $D$. frontalis appears to be composed of three major components (Fig. 2): frontalin (1,5-dimethyl-6,8-dioxabicyclo [3.2.1] octane) produced by females (Kinzer et al., 1969), male-produced endo-brevicomin [endo-7-ethyl-5-methyl-6,8-dioxabicyclo[3.2.1]octane (Vité and Renwick, 1971)], and host resin odours, particularly $\alpha$-pinene [2,6,6-trimethylbicyclo[3.1.1]hept-2-ene (Renwick and Vité, 1969)], and perhaps other monoterpenes. Female-produced trans-verbenol (trans4,6,6-trimethylbicyclo[3.1.1] hept-3-en-2-ol) may also participate but the insufficient studies to date suggest that its presence may not be essential (see below). The ternary blend is the most attractive lure yet identified for this species [at least when released in the absence of natural or artificial competing sources of attractant (Moreno et al., 2008; Sullivan and Mori, 2009; Sullivan et al., 2007b, 2011; Vité et al., 1985)], and the species possesses exceptional olfactory sensitivity to the two insect-produced components (Payne, 1975; Sullivan, 2005; Sullivan et al., 2007b). The pheromone component combination parallels that of closely related, aggressive species, $D$. brevicomis LeConte and D. adjunctus Blandford in which each sex contributes a single, different bicyclic ketal to the aggregation pheromone (ie, brevicomin or frontalin) that - at least in the case of D. brevicomis - acts synergistically (Bedard et al., 1980b; Browne et al., 1979; Byers et al., 1984; Hughes et al., 1976). This is not true for aggressive pine beetles D. ponderosae Hopkins in which females produce no bicyclic ketals (Pitman and Vité, 1969), and the close sibling of D. frontalis, D. mesoamericanus Armendáriz-Toledano and Sullivan, in which females produce both brevicomin and frontalin (Armendáriz-Toledano et al., 2015; Sullivan et al., 2012). There have as yet been no direct, experimental

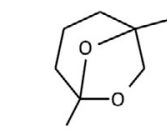

Frontalin<smiles>CC1=CCC2CC1C2(C)C</smiles>

alpha-Pinene

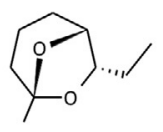

endo-Brevicomin

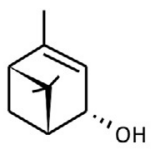

trans-Verbenol

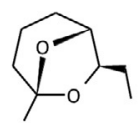

exo-Brevicomin

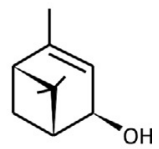

cis-Verbenol

Fig. 2 Semiochemicals capable of attracting or synergizing the attraction of flying $D$. frontalis and therefore playing a role in mediating mass-aggregation. 
contrasts of attraction between trees undergoing $D$. frontalis mass attack and the aforementioned three-component "best lure", hence it is not yet known whether the blend of three semiochemicals (with host odours considered here as a single semiochemical) truly duplicates the activity of the natural attractant.

\subsection{Frontalin}

The bicyclic ketal frontalin can arguably be named the "major component" of the aggregation pheromone/attractant for $D$. frontalis as no mixture of semiochemicals has been identified to be attractive to flying $D$. frontalis in its absence (Smith et al., 1993). It is present in newly emerged, host-arriving, and gallery-establishing females (Kinzer et al., 1969; Pitman et al., 1969; Pureswaran et al., 2007; Renwick and Vité, 1968; Sullivan et al., 2007b, 2012) and generally is undetectable in males (although see Grosman, 1996; Grosman et al., 1997; Pureswaran et al., 2006; Rudinsky et al., 1974). Evidence of its uniqueness to females is consistent with the observation that logs infested with solitary $D$. frontalis females are attractive whereas those with forced male attacks are not (Coster et al., 1977). Alone, frontalin can attract both sexes to traps; hence, it is a true aggregation pheromone (Kinzer et al., 1969; Payne et al., 1978a; Sullivan et al., 2007b). Since it is produced by gallery-establishing females and alone can attract males to females - both flying and walking - it can be described additionally as a sex pheromone component for this species (McCarty et al., 1980; NiñoDomínguez et al., 2015b; Payne et al., 1978a). It is more attractive to males than females in ambulatory bioassays (McCarty et al., 1980), and trap responses by beetles to frontalin/host-odour lures tend to be strongly maleskewed (Moreno et al., 2008; Renwick and Vité, 1969). Its attractive capacity for flying beetles is very low in the absence of host-associated synergists or trans-verbenol (discussed later), and it is possible that monoterpenes released by pines in the environment in which field bioassays were completed may have acted synergistically with frontalin in trapping trials of lures with frontalin alone (Renwick and Vité, 1970).

Dendroctonus frontalis has been reported to produce predominantly the minus enantiomer of frontalin: $85 \%$ for an unstated collection site (Stewart et al., 1977); 95\% in Mississippi, United States (Sullivan et al., 2007b), and 94\% in Chiapas, Mexico (Niño-Domínguez et al., 2015b). Compositions of $25-35 \%$ of the (-)-enantiomer were reported for beetles from South Carolina, North Carolina, and Texas, United States (Grosman 
et al., 1997), although this study had methodological problems (discussed below). EAG (electroantennogram) and GC-EAD studies indicated that antennae of both sexes of $D$. frontalis are substantially more sensitive to the (-)-enantiomer (Payne et al., 1982; Sullivan et al., 2007b). Adaptation studies indicated that beetles possess different receptors for each enantiomer, although single cell studies showed that the enantiomers stimulated the same olfactory neurons but produced differing spike frequencies (Payne et al., 1982). Adaptation to frontalin eliminates EAG responses to other semiochemicals including endo- and exo-brevicomin, trans-verbenol, verbenone, and $\alpha$-pinene, suggesting that frontalin can interact with olfactory receptors for all of these semiochemicals (Dickens, 1979; Dickens and Payne, 1977). Both enantiomers ( $\geq 98 \%$ enantiomeric purity) were attractive to $D$. frontalis both in ambulatory laboratory olfactometers and field trapping bioassays, with beetles being generally more responsive to the (-)-enantiomer (Payne et al., 1982). No difference in attraction was detected between the pure (-)-enantiomer, the approximate beetle-produced proportion of enantiomers [ie, $85 \%(-)]$, or the racemate, indicating the lack of preference for a specific ratio of the enantiomers (Payne et al., 1982). Analogues of frontalin which involved either repositioning or elimination of one or both methyl groups decreased EAG responses with the degree of response reduction being roughly correlated to the degree of modification of the analogue; however, beetles in walking olfactometers responded to all analogues (Payne et al., 1988). A weak attraction to traps was registered to only a single frontalin analogue on which the methyl group at the 1 position was moved to the 7 position (the endo- but not exo-isomer) (Payne et al., 1988; Renwick, 1970). This analogue somewhat resembles the important pheromone component endo-brevicomin except that in the latter compound the 7-position methyl is replaced with an ethyl group (Renwick, 1970). Opening of the ring structure also apparently eliminates the behavioural activity of frontalin as a flight lure (Renwick, 1970).

Early studies reported a rapid reduction of the quantities of frontalin in hindguts of females forced to attack logs, and this apparently coincided with dissapearance of droplets of trans-verbenol-dominated liquid from the hindgut (Coster and Vité, 1972; Vité and Pitman, 1968). These authors inferred that $D$. frontalis release most of their aggregation pheromone prior to entry into the host. Contrary to this, Hughes (1973) found no change in frontalin content of hindguts due to feeding. Furthermore, pine posts infested with virgin female $D$. frontalis reached maximum attractiveness after $48 \mathrm{~h}$ (Coster and Vité, 1972), and pine logs either artificially infested with beetles 
or cut from mass-attacked trees could maintain some attractiveness for multiple days (Coster et al., 1977; Franklin, 1970). Additionally, static headspace aerations (ie, involving beetles confined in still air with chemical adsorbent) indicated that emergent females released frontalin at a lower rate than females that were excised from logs after feeding for $\sim 1 \mathrm{~d}$ (Sullivan et al., 2007b; Pureswaran et al., 2008b). The opposite was observed for transverbenol, which is by far the dominant volatile compound present in the hindguts of emergent females. These data suggest that females continue to produce and release frontalin after commencement of feeding although the bulk of other volatile compounds in the hindgut at arrival (eg, transverbenol, myrtenol, cis-verbenol) apparently are released quickly and are not or only partially replaced (Sullivan, 2005; Sullivan et al., 2012). Mating may reduce production of frontalin (Sullivan et al., 2007b, 2012), although these studies confounded pairing with the female's residence time in the host. However, in an experiment in which virgin female beetles were infested onto freshly cut pine posts, attraction rapidly declined after a peak at 2 days whether or not males were added to the females' galleries (Coster and Vité, 1972). This loss in attraction may well have been due to a reduction in frontalin emission as well as to a decline in release of host odours by the ageing posts (Vité and Crozier, 1968). Frontalin emissions from gallery entrances of mass-attacked trees are significantly higher for entrances of solitary females than for entrances of pairs either before or after beginning oviposition (Pureswaran and Sullivan, 2012).

\section{3 endo-Brevicomin}

endo-Brevicomin is produced by newly emerged $D$. frontalis males, those alighting on mass-attacked trees (Pureswaran et al., 2006; Vité and Renwick, 1971), and males paired with a female in a gallery (Pureswaran and Sullivan, 2012; Sullivan et al., 2007b). For populations examined in Mississippi, United States, solitary males feeding in phloem (ie, forced to initiate a gallery on a host log, a behaviour that does not occur in nature), did not produce significantly greater amounts than newly emerged beetles whereas pairing caused production to increase nearly 10-fold (Sullivan et al., 2007b). Since production of endo-brevicomin has been shown to be stimulated in callow adult $D$. frontalis males by exposure to juvenile hormone II or its analogue methoprene (Bridges, 1982), it appears that pairing or mating may induce production of juvenile hormone in males. Male D. frontalis have been reported to produce 3\% (Redlich et al., 1987) and 
9-21\% [newly emerged beetles from Texas and the Carolinas, United States (Grosman et al., 1997)], of the (-)-enantiomer. However, studies by the author and collaborators using enantioselective GC-MS have failed to detect the (-)-enantiomer in any hindgut or aeration sample of solitary or paired D. frontalis males, including paired males from Alabama, United States, and Chiapas, Mexico, as well as newly emerged, solitary feeding, or paired individuals from Mississippi, United States (Sullivan et al., 2007b, author's unpublished data). These analyses included at least 18 samples in which the mass selective detector's threshold of detection for the (-)-enantiomer was less than $1 \%$ of the detected abundance of the $(+)$-enantiomer (Sullivan et al., 2007b). Based on these data, it can be concluded that $D$. frontalis produces little or no (-)-endo-brevicomin, although I caution that this conclusion requires broader sampling of the geographic range of $D$. frontalis.

Dendroctonus frontalis appears to have greater olfactory responses to $(+)$-endo-brevicomin than any semiochemical tested to date in GC-EAD and EAG studies. Dose-response studies indicated that olfactory sensitivity (=concentration threshold of response) of both sexes of $D$. frontalis was four orders of magnitude lower for $(+)$ than $(-)$-endo-brevicomin, and sensitivity was greater to $(+)$-endo-brevicomin than either enantiomer of frontalin (Sullivan et al., 2007b). When antennae of both sexes of $D$. frontalis were exposed in a GC-EAD analysis to 0.1 insect equivalents of a pooled hindgut extract of emerged males, endo-brevicomin generated a higher amplitude EAD response than any other compound present (Sullivan 2005). In sensory adaptation studies, endo-brevicomin occupied $75-87 \%$ of receptors on D. frontalis antennae; of tested semiochemicals only frontalin occupied more than this (Dickens, 1979; Dickens and Payne, 1977). The exceptional sensitivity of $D$. frontalis to endo-brevicomin is consistent with its having important and likely long-distance influence on the biology of this species.

Earlier behavioural studies with racemic endo-brevicomin (often released in combination with its exo-isomer) deployed in traps generally indicated that it was a potent attraction or landing inhibitor for both sexes of D. frontalis (Payne et al., 1977, 1978a; Richerson and Payne, 1979; Salom et al., 1992b; Vité and Renwick, 1971). Furthermore, across a wide range of concentrations it prevented arrestment by walking males over artificial gallery entrances releasing female-associated attractant (Rudinsky et al., 1974). In the same study it induced males to stridulate with their "rivalry" chirp, a sound which they produce during aggressive same-sex encounters (Rudinsky and Michael, 1974; Rudinsky et al., 1974; Ryker, 
1988). Thus, endo-brevicomin apparently serves as a signal of the presence of a male in a female's gallery.

Due to its consistent inhibition of attraction and production solely by the second-arriving sex, endo-brevicomin was originally classified as an antiaggregation pheromone for this species (Rudinsky et al., 1974). However Vité et al. (1985) discovered that capillaries releasing the purified (+)- or (-)-enantiomers of endo-brevicomin either enhanced or inhibited, respectively, beetle response to traps baited with attractant. They also observed some enhancement by the racemic mix of endo-brevicomin [but less than produced by pure $(+)$ ]. Additionally, they hypothesized that the failure of previous studies to detect the attractant-synergistic properties of endobrevicomin was due to the inhibitory/repellant properties of the $(-)$-enantiomer of endo-brevicomin surpassing the activity of the $(+)$-enantiomer when the racemic mixture was released at a high rate. Sullivan et al. (2007b) confirmed the strongly synergistic effect of pure $(+)$-endobrevicomin on attraction of $D$. frontalis (ie, a $\sim 40$-fold catch increase) tested within uninfested stands, however, these authors were unable to replicate the reported inhibitory effect of pure $(-)$ in field studies (unpublished data). In sum, these data seemed to be compelling evidence that $(+)$-endobrevicomin was a key component of the aggregation pheromone for D. frontalis, and, given the apparent absence of production of the antipode, that endo-brevicomin might act purely as an attractant synergist in intraspecific communication by $D$. frontalis.

However, a dose-response trapping test inside a $D$. frontalis infestation with either $(+)$-endo-brevicomin or a doubled dose of the racemate [so lure release of the $(+)$ enantiomer was equal for both treatments] found no difference in responses to either enantiomeric composition (Sullivan et al., 2011). For both (+) and racemic devices, endo-brevicomin added to frontalin and host odours did not increase attraction at any dose spanning 0.005-3 mg/d, whereas at high doses ( $>\sim 1 \mathrm{mg} / \mathrm{d}$ of each enantiomer) it significantly inhibited beetle catches (Sullivan et al., 2011). These data suggested that the attractive effects of endo-brevicomin might not be detectable or not occur inside active infestations. This hypothesis was confirmed directly in an experiment in which frontalin/host odour-baited traps were erected simultaneously inside as well as 100 and $200 \mathrm{~m}$ outside active heads of growing $D$. frontalis infestations. Addition of an identical endo-brevicomin device to these traps caused catches of $D$. frontalis to be significantly reduced within the infestations but increased outside (Sullivan et al., 2011). 


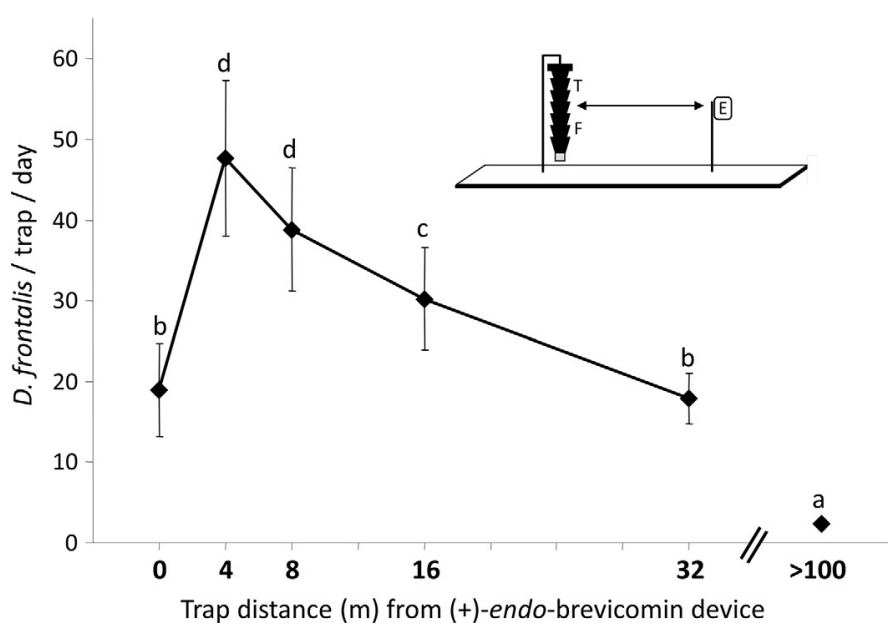

Fig. 3 Trap catches (mean \pm SEM) of $D$. frontalis in a multiple-funnel trap baited with frontalin (F) and turpentine $(T)$ and with a single device releasing $0.23 \mathrm{mg} / \mathrm{d}$ $(+)$-endo-brevicomin $(\mathrm{E})$ positioned varying distances from the trap. Traps were spaced $>100 \mathrm{~m}$ apart and the direction of the releaser relative to the trap was randomized. Figure from Sullivan and Mori (2009).

I believe that this remarkable phenomenon is at least partially explained by the fact that $(+)$-endo-brevicomin released from a point source at a rate approximately equal to a single mass-attacked tree can have synergistic effects on frontalin/host odour-baited traps located within a radius of at least $32 \mathrm{~m}$ (Fig. 3), a zone that would encompass many currently attacked and adjacent unattacked trees near the head of a beetle infestation (Sullivan and Mori, 2009). Furthermore, the synergistic effect in this study was significantly greater (ie, catches were higher) when the endo-brevicomin device was 4-16 m distant rather than on the trap. This could be due at least in part to endo-brevicomin having a "multifunctional"-type (Rudinsky, 1973a) dose-response for $D$. frontalis as illustrated in Fig. 4. In the experiment of Fig. 4, synergism by endo-brevicomin increased up to approximately $0.2 \mathrm{mg} / \mathrm{d}$ release from the trap, and then declined and finally switched to inhibition at a rate above $\sim 5 \mathrm{mg} / \mathrm{d}$. Airborne concentrations of a semiochemical decline with increasing distance from a point source. Hence one possible outcome of the multifunctional dose-response curve for endo-brevicomin would be relatively greater beetle response to release points of frontalin/host odours located at greater distances from the endobrevicomin release point as the release rate of the latter is increased above the level for optimal synergism (eg, in the curve of Fig. 4, a rate 


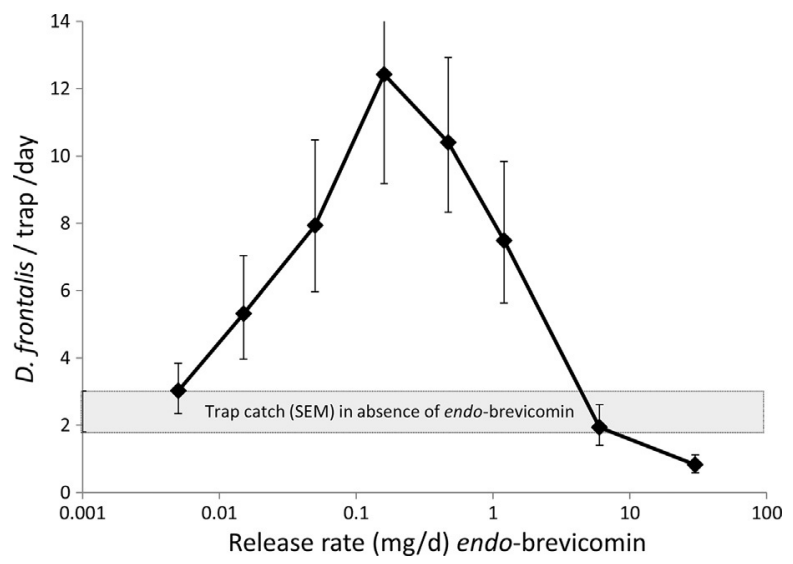

Fig. 4 Trap catches $( \pm \mathrm{SEM})$ of $D$. frontalis in multiple-funnel traps baited with $\alpha$-pinene [1-2 g/d; 23\% (+)], ( \pm )-frontalin (6-8 mg/d), and a device releasing $( \pm)$-endo-brevicomin at each of eight release rates (open-vial or capillary-type devices with different diametre openings). endo-Brevicomin devices were placed directly on traps which were located $>200 \mathrm{~m}$ apart. The grey band in the figure encloses the upper and lower bound of the SEM for the endo-brevicomin-lacking control traps. Tests were performed in mixed pine/hardwood stands during spring 2014 in Homochitto National Forest, western Mississippi, United States. Means and SEMs calculated with log-transformed catch data then back-transformed for the figure $(n=18)$.

$>\sim 0.2 \mathrm{mg} / \mathrm{d})$. Furthermore, within the active radius of "preexisting" local sources of endo-brevicomin (such as within a $D$. frontalis infestation or in the vicinity of artificial release devices) the effect of addition of endo-brevicomin releasers directly to a trap might be redundant and ineffectual, or, by augmenting the summed area-wide concentration, cause a catch reduction even though increased attraction might have been the effect in the absence of preexisting endo-brevicomin (Sullivan and Mori, 2009, author's unpublished data).

It is possible that early trapping studies did not detect the synergistic properties of endo-brevicomin for $D$. frontalis because of insufficient distance among traps and the practice by researchers of performing lure comparison trials inside or near active infestations because these locations could more readily provide statistically meaningful numbers of beetle trap catches (Payne et al., 1978a,b; Salom et al., 1992b). One implication of these findings more generally for bark beetle semiochemical research is that field experiments with unrecognized multifunctional semiochemicals could be interpreted as indicating either inhibitory/repellent or synergistic/attractive properties for the test compound depending on trap spacing (Sullivan and Mori, 2009). A similar 
problem might arise as a result of natural sources of pheromone in the environment where tests are performed. It is worthwhile noting that it is possible in bark beetles for certain pheromone components determined to be inhibitors or inactive in trapping tests to induce or increase the risk of mass attacks when deployed alone on host trees (Borden et al., 1990; Chatelain and Schenk, 1984). This implies that by their very nature trap tests can conceal potentially undesirable attractive or attack-inducing effects.

Relatively few studies have been performed on spatial effects of multifunctional or other bark beetle pheromone components, and no close parallels to endo-brevicomin's activity with $D$. frontalis have been identified in the semiochemistries of other bark beetles. Spatial separation of the releasers of the female (exo-brevicomin) and male (frontalin) contributions to the aggregation pheromone of $D$. brevicomis caused an immediate and strong decline in attraction, with a fivefold reduction in responses occurring with a mere $4 \mathrm{~m}$ separation (Byers, 1987). However, dose-dependent broadening of the zone of attraction and landing is reported to occur with the aggregation pheromones of several bark beetles. In both Ips paraconfusus Lanier and I. typographus L. the gallery-initiating, aggregation pheromone-producing sex (males) tend to land further from a source of aggregation pheromone as the concentration is increased (Byers, 1983; Schlyter et al., 1987a,b); this presumably serves to reduce intraspecific competition by allowing males to avoid areas where conspecific male densities are already high (Byers, 1989a). A similar behaviour occurs for $D$. frontalis with frontalin, where females (the gallery-initiating sex in this case) tended to land above or below the release point of frontalin whereas males landed close to the source (Hughes, 1976). This author believed that this behaviour might explain the strongly maleskewed sex ratios caught in frontalin-baited traps possessing short vertical profiles. In D. brevicomis, progressively higher rates of release of the complete aggregation attractant caused beetles to land on traps in greater relative numbers at increasing distances from the release point, and, at yet higher rates, beetle catches were reduced at the release point itself (Wood and Bedard, 1977). Similarly, frontalin will cause higher proportions of landings of D. frontalis at progressively greater horizontal distances from the pheromone release point as the release rate is increased (Vité, 1970).

However, a property that distinguishes endo-brevicomin and its behaviour from the above listed aggregation attractants which likewise cause displaced landing effects at high concentrations (besides it being a synergist and not an attractant) is that at no release rate does endo-brevicomin appear to direct landing to its point of release more than to the immediately surrounding area (Sullivan and Mori, 2009); rather, the compound apparently 
produces a zone of synergistic activity, with the release rate determining the size of the zone and the radius of maximum synergism (Sullivan and Mori, 2009, author's unpublished data). This behavioural effect also appears to occur about equally for both sexes of $D$. frontalis rather than predominantly the first arriving sex. Frontalin by contrast appears to cause landings to focus at or near its point of release, at least when it is released at low to moderate rates (Sullivan and Mori, 2009, author's unpublished data). Thus with regard to the natural colonization behaviour of $D$. frontalis, endo-brevicomin at low concentrations (as should be produced by a few arriving or paired males on the host) should enhance the attractiveness of all solitary female attacks within a certain, presumably small radius, thereby enhancing landings near these females. With increasing landings and pairings of arriving males, levels of endo-brevicomin should increase to produce synergistic effects for attacks by solitary females on trees at greater distances determined by the numbers of attacking males and thus the total release rate. Simultaneously, the increased levels of endo-brevicomin at the source trees should inhibit attraction and landing on them. Such a pheromone effect should promote and enhance switching of the attack focus by increasing the attractiveness of adjacent trees receiving pioneer female attacks while simultaneously inhibiting attraction to the previous attack focus trees.

The exo-isomer of brevicomin also occurs in small quantities in D. frontalis, and has been detected in a 1:99 to 6:94 ratio with endo-brevicomin (populations in Mississippi, Arizona, and Chiapas) (Pureswaran et al. 2008a; Sullivan et al., 2012). The quantities of endo- and exo-brevicomin produced by individual $D$. frontalis males are strongly correlated, thus their synthesis and regulation appear to be similar. As with endo-brevicomin, reported behavioural responses by $D$. frontalis to exo-brevicomin have varied. It has alternately been shown to reduce (Vité and Renwick, 1971), enhance (Hofstetter et al., 2008, 2012; Pureswaran et al., 2008a), or not significantly alter (Payne et al., 1978a) responses of $D$. frontalis to traps baited with frontalin and host odours. As with the endo-isomer, it has not demonstrated attractive properties when presented alone or with host odours. The causes of the variability in response to exo-brevicomin are unknown but could be similar as those for endobrevicomin (ie, multifunctionality). Antennal sensilla of $D$. frontalis are quite sensitive to exo-brevicomin (Payne, 1975; Pureswaran et al., 2008a). However endo-brevicomin can adapt the antennae completely to the exo-isomer whereas the reverse does not occur, suggesting that $D$. frontalis have the olfactory capacity to distinguish (and therefore behave differently) to the two forms and are more sensitive to endo- than exo-brevicomin (Dickens and Payne, 1977). Given the very small amounts of exo-brevicomin present in 
D. frontalis, the compound may not function as a pheromone per se, but the beetles' responses may reflect interspecific interactions with species that produce larger quantities. As previously mentioned, the black turpentine beetle D. terebrans releases exo-brevicomin as part of its pheromone (Payne et al., 1987; Phillips et al., 1989), and D. frontalis cross-attraction to exo-brevicomin from this species could aid it in locating and exploiting lightning struck or other compromised hosts discovered by D. terebrans (Smith et al., 1990). Similar cross-attraction may occur in the sympatric zone of $D$. frontalis and D. brevicomis located in the southwestern United States, as the latter produces exo-brevicomin as an important component of its aggregation pheromone and the two species frequently cohabit the same host trees (Davis and Hofstetter, 2009; Hofstetter et al., 2008; Pureswaran et al., 2008a).

\subsection{Host Monoterpenes}

Aggregation pheromone components of $D$. frontalis (frontalin alone or in combination with endo-brevicomin) are strongly synergized by odours of host resin. Raw pine oleoresin strongly synergized responses of flying D. frontalis to frontalin (Kinzer et al., 1969), and distilled pine oleoresin (turpentine) from host pines of $D$. frontalis also had a strong synergistic attractive effect on frontalin alone as well as the combination of frontalin and endobrevicomin (Payne et al., 1978a; Sullivan et al., 2007b). Addition of $\alpha$-pinene to lures of frontalin and trans-verbenol caused a greater increase in responses of flying $D$. frontalis than did addition of other major monoterpene components of the oleoresin of $D$. frontalis host species (ie, $\beta$-pinene, camphene, myrcene, limonene, 3-carene, 4-allylanisole, and terpinolene), although this result requires confirmation as no statistical data were presented (Renwick and Vité, 1969). $\boldsymbol{\alpha}$-Pinene was likewise found to be a superior synergist to myrcene in frontalin lures for $D$. frontalis in Arizona (Hofstetter et al., 2008). This preference may reflect $\alpha$-pinene being the predominant component of the resins of the common host species for $D$. frontalis including (in the eastern United States) P. taeda L., P. echinata Mill., P. pallustris, P. ellioti Engelm., P. strobus L., P. rigida Mill., and P. virginiana Mill. (Mirov, 1961). The (+)-enantiomer of $\alpha$-pinene is a better synergist than the (-)-enantiomer, and EAG cross-adaptation studies indicated that both sexes possess at least some receptors with differing affinities for the two enantiomers (Staeben et al., 2015). The antennae also have a lower response threshold to $(+)$ than $(-)-\alpha$-pinene. The capacity to distinguish $\alpha$-pinene enantiomers may mediate selection of species of host or 
individual trees with a higher $(+)$-content to their resin, but this possibility and its possible biological significance have not been investigated. The synergistic effects of high rates of host odours are quite dramatic. Billings (1985) observed that a high release rate of turpentine $(3.6 \mathrm{mg} / \mathrm{d})$ could enhance mean D. frontalis trap catches with a frontalure bait (ie, a 1:2 blend of frontalin and $\alpha$-pinene released at $50 \mathrm{mg} / \mathrm{d}$ ) almost 30-fold. In Mississippi, an approximate 100-fold increase in the release rate of turpentine from traps caused a nearly 10-fold increase in catches both when the pheromone lure was either frontalin and endo-brevicomin or frontalin alone (Fig. 5). Addition of a device releasing $P$. taeda-derived turpentine at $7 \mathrm{~g} / \mathrm{d}$ to traps with a frontalin/(+)-endo-brevicomin lure enhanced catches 45-fold (Sullivan et al., 2007b). This response may reflect the fact that pines undergoing mass attack by $D$. frontalis release very large amounts of host odours, with individual attacks releasing an average of $14.4 \mathrm{mg} / \mathrm{d} \alpha$-pinene and with beetle attacks typically occurring in the thousands on mass-attacked trees (Pureswaran and Sullivan, 2012). These quantities decline substantially once

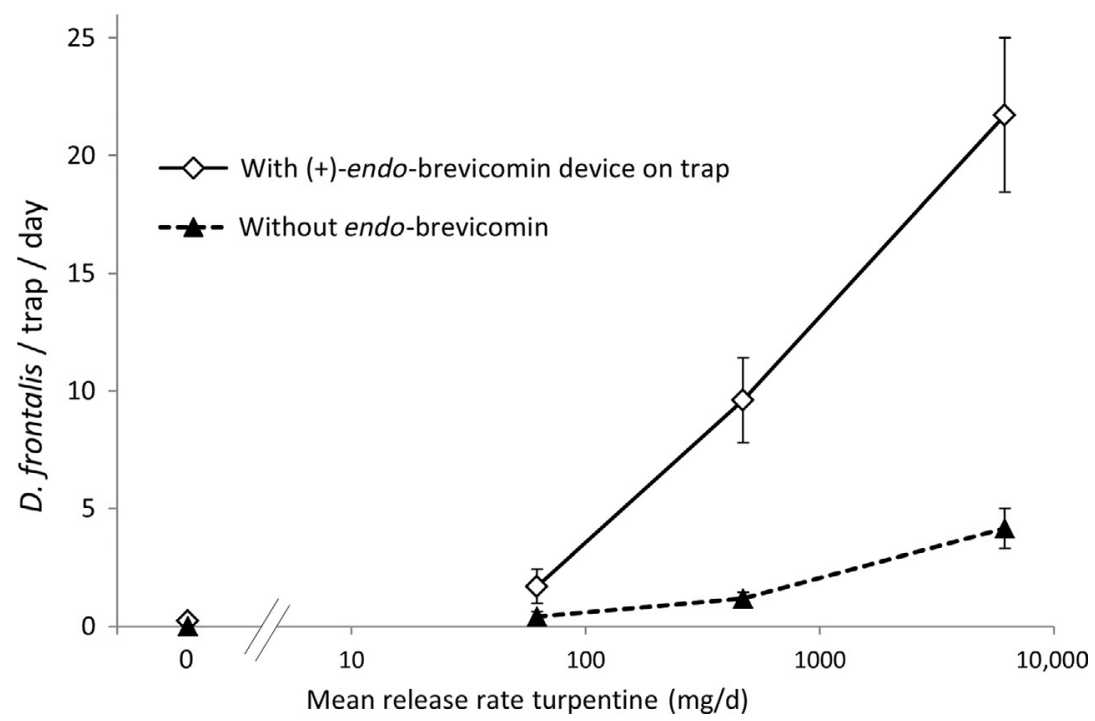

Fig. 5 Effect of varying the release rate of a blend of host odours (ie, distilled P. taeda turpentine) on catches of $D$. frontalis in multiple-funnel traps baited with $( \pm)$-frontalin $(\sim 5 \mathrm{mg} / \mathrm{d})$ released either alone or with a $(+)$-endo-brevicomin device (releasing $0.23 \mathrm{mg} / \mathrm{d}$ ) on the trap. The test was performed in mixed pine/hardwood stands during late winter/spring of 2007 in the Homochitto National Forest, western Mississippi, United States $(n=24)$, and traps were located $>150 \mathrm{~m}$ apart. Release rates for lures were determined gravimetrically in a fume hood. 
mass attack is complete. Individual entrances of attacking $D$. frontalis release the attractive synergist $\alpha$-pinene at three to four orders of magnitude greater amounts than the beetles release their pheromone components (Pureswaran and Sullivan, 2012).

$\alpha$-Pinene is abundant in the atmosphere of pine forests (Seybold et al., 2006) and is produced by a great diversity of tree species. Therefore, the mere presence of $\alpha$-pinene should provide little if any specific information to a dispersing, host/mate-seeking bark beetle. Relatively low olfactory sensitivity to $\alpha$-pinene by $D$. frontalis (Dickens and Payne, 1977; Payne, 1975) is likely a reflection of this. Higher concentrations may provide information regarding host species (ie, high levels of $\alpha$-pinene are associated with conifers) and its release could signal the presence of an insect attack or an injury that might render the tree more susceptible. It may also communicate the defensive capabilities of the potential host, as has been suggested to occur for less aggressive bark beetle species that are attracted to modest concentrations of host monoterpenes but repelled by higher ones (Erbilgin et al., 2003). Host monoterpenes are toxic to bark beetles (Cook and Hain, 1988; Everaerts et al., 2012), and presumably airborne resin terpene concentrations that exceed a certain threshold should signal a host whose defensive response may be greater than can be withstood by the host-seeking species (Erbilgin et al., 2007b). The very high rates of turpentine odours preferred by $D$. frontalis are simultaneously inhibitory to their significant competitor I. avulsus (Billings, 1985). Attractive synergism by very high amounts of $\alpha$-pinene may be a means for outbreak-level $D$. frontalis to select trees that are too vigorous to be colonized by less aggressive competitors, and thus this behaviour may reduce interspecific competition.

\section{5 trans-Verbenol}

In addition to frontalin, D. frontalis females produce trans-verbenol, which is found in very large quantities in emergent brood females (ie, microgram amounts) as well as in those initially arriving on the host (Pitman et al., 1968; Pureswaran et al., 2006, 2008a; Renwick, 1967; Sullivan et al., $2007 b$ ). It apparently is released quickly upon landing or gallery initiation since feeding females-both solitary and paired with males inside galleries - contain and release much smaller amounts, even within a few hours after entering a host (Coster and Vité, 1972; Hughes, 1973; Pureswaran et al., 2006, 2008b; Sullivan et al., 2012). Its presence is strongly sexually dimorphic in newly emerged beetles (Renwick, 1967) with females 
containing 10 to $>1000$ times more than emerged males (Grosman et al., 1997; Pureswaran et al., 2008a; Sullivan et al., 2012). Its production is stimulated in newly enclosed adults of both sexes by exposure to juvenile hormone II or its analogue methoprene (Bridges, 1982). In studies which lacked statistical analysis, trans-verbenol sprayed onto the boles of trees under attack did not alter beetle landings (Vité and Crozier, 1968), but it increased responses to field "sleeve" olfactometers baited with frontalin and a low release rate of verbenone (Renwick and Vité, 1969). Payne et al. (1978a) found that trans-verbenol significantly increased $(\sim 2.5$-fold) $D$. frontalis response to traps baited with frontalin, although its enhancing effect was duplicated by releasing host turpentine at a 12-fold greater rate than either compound, and their data likewise indicated a similar redundancy of effects between trans-verbenol and $\alpha$-pinene. This finding is consistent with the observation that addition of oleoresin, which is a potent synergist of frontalin (Kinzer et al., 1969), had no effect in the field on increasing the attractiveness of crushed beetles which presumably would have released large quantities of trans-verbenol (Vité and Renwick, 1968). The apparently redundant effects of trans-verbenol and host odours on attraction of flying $D$. frontalis may function in allowing first-arriving $D$. frontalis to initiate concentration on a host before the phloem is penetrated and host resin is released (Renwick and Vité, 1969, 1970). This hypothesis is consistent with the observation that in the first stage of mass attack $D$. frontalis will congregate under bark flakes of a target tree prior to mining into the bark in apparent synchrony (Hopkins, 1909; Vité and Crozier, 1968; Vité and Renwick, 1968). This hypothesis is provocative since if beetle concentration were completed prior to entry of the phloem, much of the selective pressure against pioneering behaviour (Latty and Reid, 2010; Pureswaran et al., 2006) would be alleviated. Once resin exudation by the damaged host has been triggered, it is presumed that trans-verbenol is no longer relevant to mass attack (Renwick and Vité, 1969). It is likely for this reason that trans-verbenol has received very little attention or additional research in efforts to develop semiochemical-based management for D. frontalis. Given that most of the female's large "store" of trans-verbenol appears to be released before entry into the bark, it is possible that trans-verbenol may play a more important role in close-range interactions by beetles on the bark surface (Bunt et al., 1980) rather than or in addition to functioning as a longrange component of the aggregation pheromone. The enantiomeric ratio produced by females has been measured as 60:40 and 25:75 (+)/(-) (Grosman et al., 1997; Plummer et al., 1976), although this ratio is likely 
influenced by the enantiomeric composition of $\alpha$-pinene of the host tree. In the mountain pine beetle, D. ponderosae, trans-verbenol is the major component of the aggregation pheromone released by solitary females attacking a host and acts synergistically rather than redundantly with host odours (Pitman and Vité, 1969; Skillen et al., 1997). In the western pine beetle, D. brevicomis, it is released by arriving females but appears to act as a multifunctional pheromone component, enhancing attraction at a low release rate but decreasing it at a high rate (Bedard et al., 1980a; Byers et al., 1984).

cis-Verbenol is also produced by $D$. frontalis females in modest quantities (Grosman et al., 1997; Hughes, 1973; Pitman et al., 1969; Renwick et al., 1973), and one trapping study indicated that a high release rate $(\sim 50 \mathrm{mg} / \mathrm{d})$ of the compound could enhance $D$. frontalis responses to traps baited with frontalin and a low release of $\alpha$-pinene (Sullivan, 2005). However, significant levels of trans-verbenol contamination (1-2\%) in the cis-verbenol lures in this study could have produced some or all of the attractive effect. cis-Verbenol is produced by and has been shown to enhance aggregation in D. ponderosae (Miller and LaFontaine, 1991) although it appears to be a far more important component in the pheromone composition of Ips spp. (Lanier and Wood, 1975; Vité et al., 1972).

\subsection{Role of the Two Sexes in Mediating Mass Aggregation}

Early papers on the chemical ecology of $D$. frontalis implied that females were entirely responsible for producing the aggregation pheromone whereas males produced compounds that mediated termination of aggregation and switching of the focus of mass attack (Renwick and Vité, 1970; Vité and Francke, 1976). This conclusion arose because the two major active compounds which appeared to distinguish males (ie, verbenone and endobrevicomin) inhibited responses to attractant-baited traps (Payne et al., 1978a; Renwick and Vité, 1969; Vité and Renwick, 1971). However, attractiveness of artificially infested logs was found to not differ significantly depending upon whether females alone or pairs were present (Coster and Vité, 1972; Coster et al., 1977; Svihra, 1982). These results were inconsistent both with the original hypothesis that the males produce attraction inhibitors and the subsequent discovery that endo-brevicomin can be a potent synergist of beetle attraction (Sullivan et al., 2007b; Vité et al., 1985). However, when healthy pines spaced $>100 \mathrm{~m}$ apart and screened from wild attacks were infested with groups of 100 females, addition of 
100 male beetles increased conspecific attraction approximately sixfold over trees to which no males were added (Sullivan et al., 2007b). The inconsistency between the standing tree and log experiments could be related to the relatively higher resin exudation from attacks on the live, vigorous trees (Vité and Crozier, 1968; Vité and Renwick, 1968) and the fact that logs are an unnatural host substrate for $D$. frontalis. Additionally, two of the aforementioned bolt studies were performed in close proximity to $D$. frontalis infestations (Coster and Vité, 1972; Coster et al., 1977); the third did not indicate the relative proximity of the study site to infestations (Svihra, 1982). As discussed earlier, close proximity to active infestations may conceal the attractive effects of endo-brevicomin (Sullivan et al., 2011), apparently due to the pheromone component's area-wide synergistic activity.

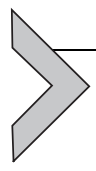

\section{SEMIOCHEMICAL INHIBITION OF CONCENTRATION (ANTIAGGREGANTS)}

This list (Figs 6 and 7) includes all compounds (except endobrevicomin, the multifunctional pheromone component which has already been thoroughly discussed) produced by a range of sources, including the beetles themselves, that individually have exhibited the capacity to reduce responses of $D$. frontalis to attractive lures. For compounds produced by the beetles themselves that reduce response to aggregation attractant, the presumed function is as a pheromone which communicates that the host resource has been fully exploited (ie, that there is not sufficient quantity

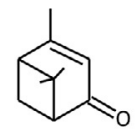

Verbenone

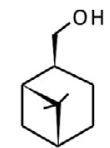

cis-Myrtanol

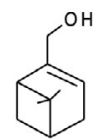

Myrtenol

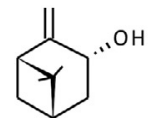

trans-Pinocarveol

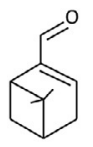

Myrtenal

trans-Myrtanol

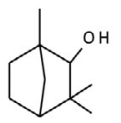

Fenchyl alcohol

Fig. 6 Oxygenated monoterpenes released by one or both sexes of $D$. frontalis which are capable at some concentration of reducing flying $D$. frontalis response to attractants, and thus these may play a role in terminating mass attack, switching of attack focus to adjacent trees, or indicating exhausted and unsuitable hosts. Both verbenone and myrtenol have been classified as "multifunctional" on the basis of their attractive synergism when presented in low doses in ambulatory olfactometer assays. 


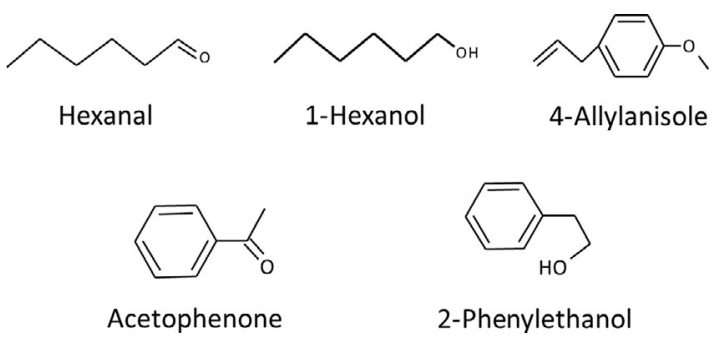

Fig. 7 Non-terpene semiochemicals shown capable individually of inhibiting response of flying $D$. frontalis to attractants. Hexanol and hexanal are "green leaf volatiles" common to deciduous trees; 4-allylanisole is a component of host pine resin. Acetophenone and 2 -phenylethanol are produced in small quantities by both sexes of $D$. frontalis and occur in other species of bark beetles and beetle-associated microbes.

or quality of host tissue left available, or-for males-that all available females have paired). Presumably, host/mate-availability-communicating or attack spacing (epideictic) pheromones might be produced by either or both sexes; this is because the outcome should benefit both sexes (and both the signal sender and receiver) by reducing competition for resources by their offspring (Borden, 1997; Byers, 1989a). Semiochemicals that indicate saturation or onset of host tissue unsuitability on a tree undergoing attack could arise from the host tree itself or from other host tissue-colonizing associates including arthropods and microbes.

\subsection{Verbenone}

The occurrence of verbenone (4,6,6-trimethylbicyclo[3.1.1]hept-3en-2-one) in male $D$. frontalis has much similarity to trans-verbenol in females: emergent males contain quantities which are so great (ie, microgram amounts) as to be apparent as verbenone-dominated droplets of oil in excised hindguts whereas emergent females contain merely nanogram quantities of verbenone (Vité and Crozier, 1968). Likewise these droplets disappear and the quantities measured in hindgut extracts decline rapidly following the male's entry into the bark (Pitman et al., 1968; Pureswaran et al., 2007; Vité and Crozier, 1968). Forcing a solitary male to chew into the bark by confinement appears to cause a similar drop in presence of verbenone as does pairing with a female, suggesting the reduction is due to defecation of the hindgut-stored quantities of the compound and not mating (Sullivan et al., 2007b). Nonetheless, despite this apparent depletion of verbenone amounts in the gut and reduction of amounts in headspace aerations of isolated male beetles before vs after feeding (Pureswaran et al., 2007), aerations 
of trees undergoing mass attack indicated that entrances of beetle pairs released about twice as much verbenone as entrances of solitary females (Pureswaran and Sullivan, 2012).

Verbenone is frequently called an "antiaggregation pheromone" for D. frontalis [and several other species of Dendroctonus (Skillen et al., 1997)] based largely on its capacity to reduce beetle responses to attractant-baited traps, and the endurance of this label may be due in part to verbenone's being the first bark beetle-produced compound discovered with anti-attractive effects and therefore to be hypothesized to play a role in terminating mass attack in a bark beetle (Renwick and Vité, 1969). The activity originally proposed for this compound in nature (Renwick and Vité, 1969, 1970) was that at relatively low concentrations (ie, as a mass attack was building) it reduced responses of males thereby bringing the strongly male-biased sex ratio attracted by frontalin closer to $1: 1$. Higher concentrations inhibited catches of both sexes and were presumed to coincide with host resource depletion, the termination of frontalin production by females, as well as the cessation of resin exudation by the host (Renwick and Vité, 1969). The dose-effect of verbenone on responses to $D$. frontalis to attractant was confirmed in field trials which produced a progressively lower representation of males and then an overall reduction in responding beetles as release rates were increased from 12 up to $240 \mathrm{mg}$ per day (Payne et al., 1978a).

However, the lowest release rate devices that have been shown to reduce D. frontalis responses to attractant-baited traps $(\sim 25 \mathrm{mg} / \mathrm{d})$ have a greater rate than that of verbenone expected from a single tree undergoing mass attack ( 10 mg/d) (Pureswaran and Sullivan, 2012; Salom et al., 1992b). Furthermore, sixteen $5 \mathrm{mg} / \mathrm{d}$ devices distributed evenly about the bole and releasing $80 \mathrm{mg} / \mathrm{d}$ in total failed to stop mass attack, reduce landings, or hinder brood production by $D$. frontalis in the treated pines (Richerson and Payne, 1979). These data imply that the levels of verbenone released by males on a mass-attacked tree should not be sufficient to alter the progression of a mass attack. Furthermore, aforementioned evidence suggesting that males release much of their verbenone between landing and pairing (ie, when mass attack is ongoing) indicates that the timing of release is not consistent with a major role in shutting down mass attack, an observation that was also made for verbenone as an attraction inhibitor in $D$. brevicomis (Byers et al., 1984).

Verbenone was also classified as a "multifunctional" pheromone because in laboratory tests low concentrations of verbenone increased the frequency that males were arrested over an artificial female entrance releasing female 
pheromone components; higher concentrations of verbenone caused males to pass the entrance (Rudinsky, 1973b). However, field trapping trials have never demonstrated attraction enhancement of males at any dose tested [although a sufficiently broad "dose-response" test has never been performed (Payne et al., 1978a; Salom et al., 1992a; Sullivan et al., 2007a)]. However, in a single trial of one study (Salom et al., 1992b), a verbenone lure with a high proportion of the (+)-enantiomer significantly enhanced responses of females to attractant-baited traps.

There is also some imprecision in applying the name "pheromone" to verbenone (and, actually, to many oxygenated monoterpenes produced by bark beetles) because it has many sources in nature. Verbenone (and verbenol) can be generated through autoxidation of host-released $\alpha$-pinene coming into contact with atmospheric oxygen (Hunt et al., 1989; Moore et al., 1956). Microbes including bark beetle symbionts and incidental associates are also capable of oxidizing $\alpha$-pinene to verbenol and/or verbenol to verbenone (Borden et al., 1986; Brand et al., 1975; Hunt and Borden, 1990; $\mathrm{Xu}$ et al., 2015). A fungus carried in the mycangium of female $D$. frontalis (Ceratocystiopsis ranaculosus J.R. Bridges and T.J. Perry) was shown to convert verbenol to verbenone (Brand et al., 1976). However, no tests have been reported which demonstrate that such microbes make a significant contribution to semiochemical production by $D$. frontalis-attacked trees in nature, or whether microbial activities have an impact on the species' chemical ecology more generally.

\subsection{Other Oxygenated Monoterpenes}

In addition to verbenol and verbenone, $D$. frontalis produce a number of other oxygenated monoterpenes some which have demonstrated behavioural activity with conspecifics (Smith et al., 1993) and appear to be derived from precursors in the host oleoresin (Hughes, 1973; Renwick et al., 1973). It is likely that many if not most of these oxygenated monoterpenes arise through a non-specific enzymatic oxidation of unsaturated hydrocarbon molecules at an allylic position, and thus a process that may not necessarily be unique to monoterpene substrates (Renwick and Hughes, 1975). These non-specific oxidations of host monoterpenes were demonstrated through exposure of $D$. frontalis (and other bark beetles) to vapours or cuticular contact with different individual monoterpenes; this resulted in appearance or increase in concentrations of the allylic oxidation products of those specific terpenes (Renwick et al., 1973, 1976a). Such direct oxidations of host 
monoterpenes have been confirmed in D. ponderosae using labelled substrates (Gries et al., 1990a). Quantities produced were dependent on the length of time of exposure, and occurred despite removal of chemical sensory organs, suggesting that the production was not under regulation by feedback through the central nervous system. The existence of non-specific terpenoid oxidation mechanisms likely has its origins in the beetle's need to detoxify the monoterpenes to which they are exposed during invasion of the host (Blomquist et al., 2010; Seybold et al., 2006), as oxidation increases solubility and facilitates elimination (Harborne, 1988). Because of the shared need to detoxify resin of similar monoterpene compositions, pine beetle species tend to produce many of the same oxygenated monoterpenes "randomly" (Francke and Vité, 1983), and thus these products can provide little signal specificity or consistency. However, the spectrum and prominence of specific oxidation products may differ among species and between sexes [for example, $D$. frontalis males produce almost entirely monoterpene aldehydes and ketones whereas females appear to be limited largely to producing alcohols (Renwick et al., 1973)]. This implies that oxidases with differing degrees of substrate affinity vary in their abundance among bark beetle species and sexes.

A diversity of such oxygenated terpenes has been identified from D. frontalis; most occur in relatively small quantities, and several have exhibited behavioural activity (Sullivan, 2005). Myrtenol occurs in both sexes of D. frontalis (Grosman et al., 1997; Renwick et al., 1973; Sullivan et al., 2012), and laboratory assays indicated a "multifunctional" behavioural response to this compound, with low concentrations increasing beetle arrestment at artificial female entrances and with higher concentrations inhibiting arrestment (Rudinsky et al., 1974). Devices releasing $1.5-3 \mathrm{mg} / \mathrm{d}$ significantly reduced $D$. frontalis catches in traps baited with frontalin and $\alpha$-pinene (Sullivan et al., 2007a). Myrtenal, trans-pinocarveol, cis-myrtanol, trans-myrtanol, and fenchyl alcohol are produced by both emergent and feeding $D$. frontalis and elicit EAD responses; at a release of $\leq 66 \mathrm{mg} / \mathrm{d}$ all significantly reduced $D$. frontalis responses to traps baited with frontalin and $\alpha$-pinene (Sullivan, 2005). Several of these compounds are produced by the beetles in very small quantities and it is unclear whether the inhibition of attraction reflects their having a function in mediating intraspecific interactions in nature, a requirement for classifying these compounds as "genuine" pheromone components. Rather, these and additional common oxygenated monoterpenes may be more general infochemicals which indicate the early stages of a decaying and thus unsuitable host 
(Flechtmann et al., 1999; Lindgren and Miller, 2002). As with verbenone, many may be generated through the enzymatic oxidation activities of microbes in the host tissues or autoxidation of host resin (Flechtmann et al., 1999; Hunt et al., 1989; Sullivan, 1997; Sullivan et al., 2000).

\subsection{Non-Monoterpene Aromatics}

Both sexes of $D$. frontalis produce both acetophenone and 2-phenylethanol in small amounts whether newly emerged, feeding solitary, or paired (Sullivan, 2005; Sullivan et al., 2012). Both compounds inhibit responses of flying beetles to traps baited with frontalin and $\alpha$-pinene (Sullivan, 2005; Sullivan et al., 2007a), and 2-phenylethanol reduced responses of beetles to attractant in an ambulatory olfactometer (Brand et al., 1977). These compounds have been detected in other species of Dendroctonus and Ips (Kohnle et al., 1987; Pureswaran and Borden, 2004; Pureswaran et al., 2000; Renwick et al., 1976b; Zhang et al., 2007), and have demonstrated behavioural activity with some (Erbilgin et al., 2007a, 2008; Pureswaran et al., 2000). It was shown in Ips pini that 2-phenylethanol is generated from the amino acid phenylalanine, and both this compound and acetophenone appear to be amino acid derivatives (Gries et al., 1990b; Seybold and Vanderwel, 2003). 2-Phenylethanol is also generated by microbial associates of $D$. frontalis growing in culture (Brand et al., 1977).

\section{ATTACK SEQUENCE}

Fig. 8 illustrates the process by which a $D$. frontalis infestation becomes initiated and begins to grow through the mediation of semiochemicals discussed above. The functional roles of most individual compounds are not well studied and what we know of them is based on inferences from field trapping experiments and walking olfactometer trials in the laboratory. Therefore this "model" like those that have been published in the past, eg (Payne, 1980; Renwick and Vité, 1969, 1970) is largely conjecture beyond the information detailed earlier in this review, and the model should be treated merely as a likely scenario given the limited available data.

\subsection{Establishment and Initiation of Spot Growth}

Infestations most frequently originate in the spring which is the major period of D. frontalis dispersal (Thatcher and Pickard, 1964, author's unpublished 


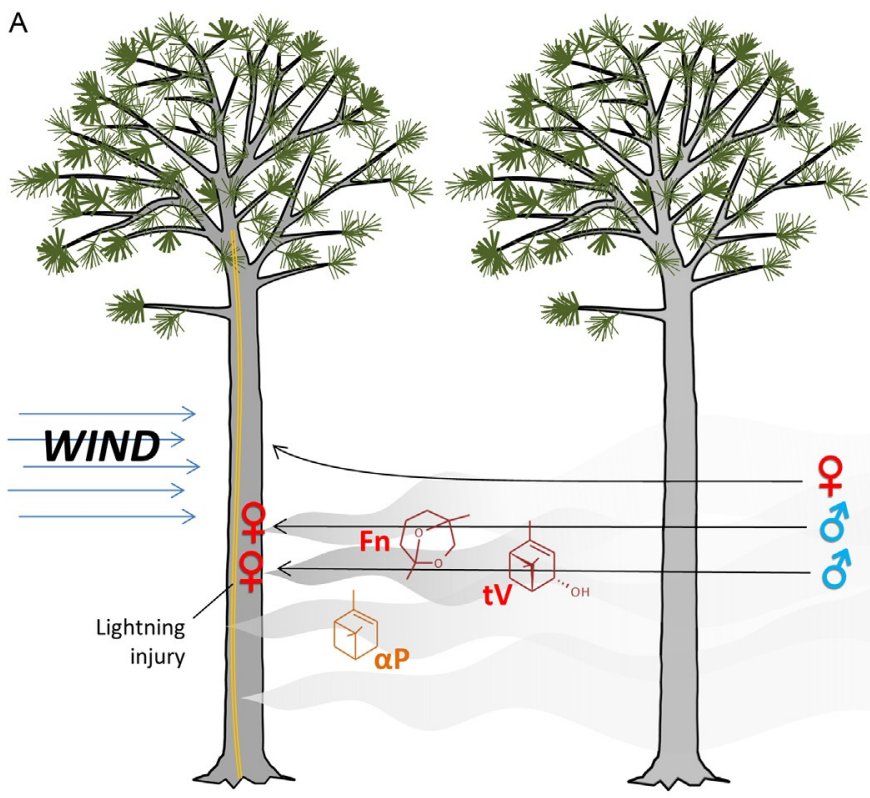

Pioneer attacks

and recruitment

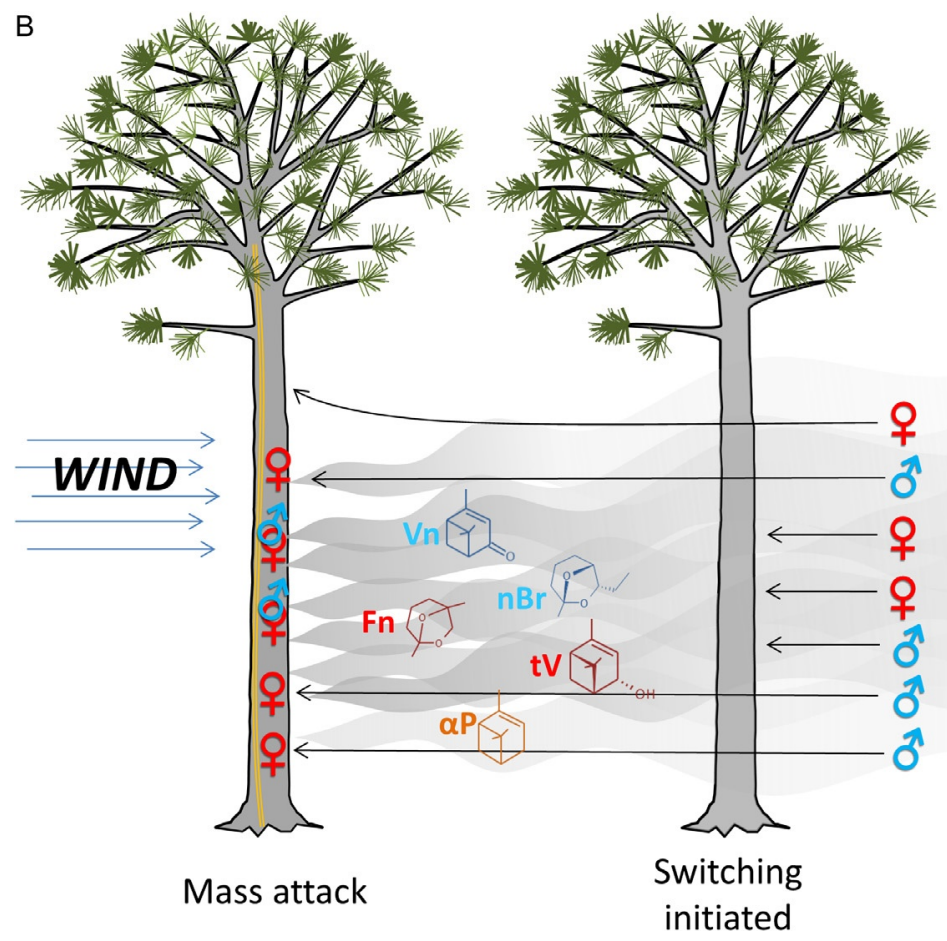

Fig. 8-Cont'd 


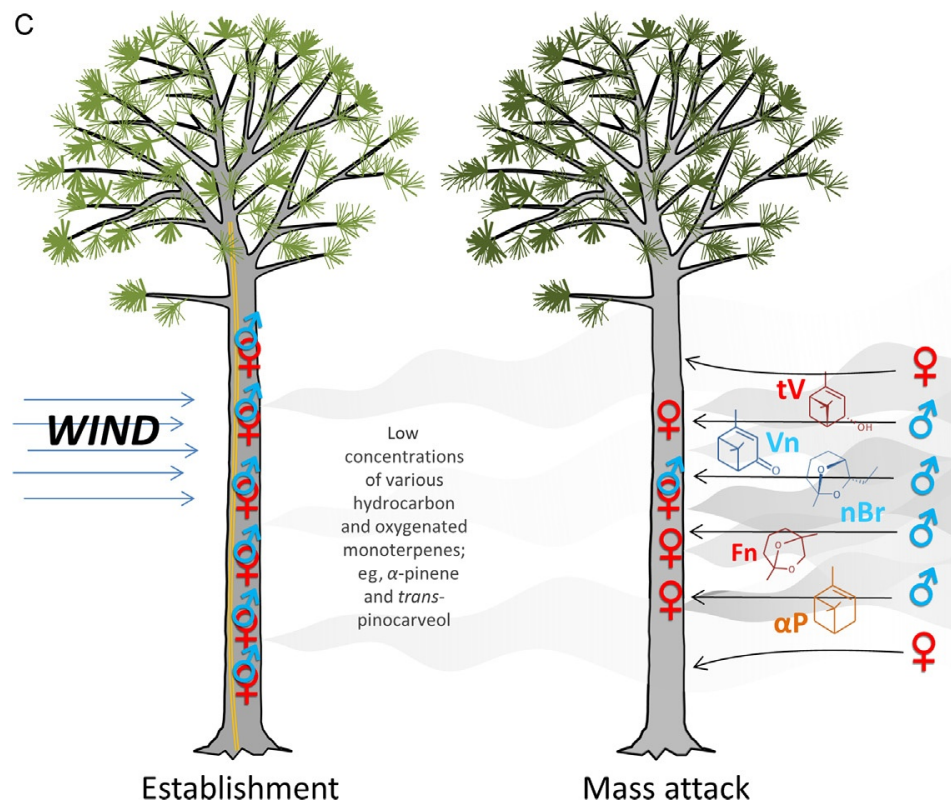

Fig. 8 (A) Stage I: Initiation of a $D$. frontalis infestation. Dispersing pioneer female beetles locate a lightning-weakened (or otherwise susceptible) pine apparently by random searching. They then release frontalin (Fn) and trans-verbenol (tV) which function synergistically to attract conspecifics of both sexes. Host-produced $\alpha$-pinene $(\alpha P)$ from the lightning wound (and later from the females' entrances once they penetrate the phloem) may act as a synergist that duplicates the effects of the trans-verbenol. Attacking females establish nuptial chambers if resin defences are sufficiently low; otherwise they may expel resin from the gallery entrances to form pitch-tubes while continuing to release aggregation pheromone. endo-Brevicomin (not shown) from the first arriving males synergizes attraction to the pheromone-releasing females. Further arriving females, deterred by high concentrations of frontalin odours, tend to land above and below the area of initial female attack at mid-bole. (B) Stage II: Mass attack and initiation of switching of attack focus to an adjacent tree. Large numbers of beetles of both sexes arrive on and attack the original pine in response to the aggregation attractant of the first and subsequent arrivers. Males locate attacks of females and pair with them; they assist the female with clearing the gallery entrance while they simultaneously release both verbenone $(\mathrm{Vn})$ and endo-brevicomin $(\mathrm{nBr})$. These two compounds indicate to mate-seeking males on the bark surface that a female in an entrance has already paired, in which case a searching male must either remove the occupying male forcefully or continue looking for an unpaired female. At high concentrations (ie, with a high density of males), endo-brevicomin may also deter beetle landing, as may verbenone. However, male-produced endo-brevicomin strongly synergizes responses of flying beetles to solitary female attacks within a distance of at least several metres of the releasing males, and this aids in synergizing responses of beetles to "pioneer" female attacks on surrounding trees. Paired females on the original tree continue to release frontalin $(\mathrm{Fn})$ and trans-verbenol (tV) at reduced levels, and synergistic $\alpha$-pinene continues to be 
data). Dispersing females may locate a standing tree weakened by a disturbance (such as a lightning strike) or other cause, land near mid-bole (Coster et al., 1977), and begin releasing pheromone and perhaps initiate attack on the bark (Fig. 8). High levels of $\alpha$-pinene released from the tree's injuries may arrest dispersing beetles post-landing, but there is no evidence that a primary attractant draws $D$. frontalis pioneer females to a susceptible tree. However, the $\alpha$-pinene released from the injury should nonetheless act as a synergist for the frontalin being released by the pioneer females and thus increase attraction. The pheromone release by the pioneer females (frontalin and to a lesser extent trans-verbenol) plus the host odours from the tree attract dispersing beetles of both sexes to the tree which, through the positive feedback of increasing numbers of attacking beetles and associated increasing pheromone, trigger mass attack. Males that land and pair with females release large quantities of verbenone and lesser quantities of endo-brevicomin. The endo-brevicomin released by the initially arriving males synergizes the attraction of both sexes to female attacks on the tree. Arriving females avoid landing close to areas of high release of frontalin produced by earlier female arrivals and instead land above or below the portions of the bark already colonized by females. This may in part cause the expansion of the infested portions of the bole both upward and downward (Hughes, 1976). For reasons already discussed, the precise role of verbenone in regulating mass attack-if any-is uncertain.

Fig. 8-Cont'd released from damaged host tissue. A plume of attractant and synergists encompasses downwind, unattacked trees; upwind-orienting (anemotactic) females land on them and may begin to bore if the semiochemical concentration of the engulfing plume is sufficiently elevated. These attacks initiate the shift of the focus of attack to the downwind tree. (C) Stage III: Termination of attack on the original tree and re-focus of attack onto the "switch tree". After the original tree ceases to produce a constitutive resin response and has reached its carrying capacity of parent beetle pairs, each pair plugs its gallery entrance with frass and begins to extend the gallery in the phloem while laying eggs. This event coincides with a substantial reduction in semiochemical release (particularly of beetle pheromone components) from the original tree. Nonetheless, the tree continues to release odours for many weeks, including a variety of possibly inhibitory/ repellant oxygenated monoterpenes generated from spontaneous and microbially mediated oxidation of the dead host's residual resin monoterpenes. The foliage of the tree crown begins to fade at this time. Meanwhile, a mass attack proceeds on the new focus tree as it had on the original tree, with its resulting semiochemical plume likewise being capable of starting attacks on nearby, particularly downwind trees. Parent adults reemerging from the original tree (and later, the emerging, developed brood) may participate in mass attack of new focal trees, and thus these beetles may initiate and then maintain a continuous cycle of new attacks by both re-emergent parents and newly emerged brood beetles that can propel a steadily growing infestation and continue to consume trees over a period of months. 
The plume of pheromone components is carried downwind where, if it engulfs a nearby host pine and the frontalin in the plume is of sufficiently high concentration, upwind-flying females responding to the attractant will be stimulated to land, release pheromone, and possibly begin mining into the tree (Gara, 1967; Gara et al., 1965) (Fig. 8B). endo-Brevicomin released by the growing number of males on the original tree should tend to synergize frontalin released from increasingly more distant attacks by solitary females (ie, including downwind trees) while reducing synergism and attraction at and close to the point of release. The combined effects of the high concentrations of frontalin and resin odours (and possibly also trans-verbenol) engulfing the adjacent trees, and the synergistic effects of endo-brevicomin, result in increasing attacks on one or more adjacent and typically downwind trees (Gara and Coster, 1968). Landings and attacks on the original tree decline as all of the available host tissue becomes colonized (ie, the host reaches saturation), and established beetle pairs cease producing pheromone components as they proceed to mine into the phloem and close-off the gallery entrance with their frass. This is accompanied by a decrease in resin exudation by the host tree (Vité and Crozier, 1968), an event that reduces release of synergistic $\alpha$-pinene (Pureswaran and Sullivan, 2012). The newly attacked trees then exceed the attractiveness of original tree and therefore become the new foci of attack. The process of "switching" is then complete (Fig 8C). The pheromone plume from the newly mass-attacked trees then in turn induces attacks on adjacent healthy trees and propels the cycle of spot growth.

\subsection{Persistence and Termination of Spot Growth}

As implied by the above model, spot growth can persist only as long as there are (1) attacked trees releasing pheromone and host odours at sufficient rates to induce attacks on adjacent trees (Gara and Coster, 1968) (2) suitable uninfested trees adequately close to the pheromone source tree(s) that landing and mass attack can be induced on them by the semiochemical plume (Johnson and Coster, 1978; Schowalter et al., 1981) and (3) local beetle population levels that are sufficient to successfully mass attack the "next" tree(s) (Clarke, 2012; Gara and Coster, 1968). The obstacle posed to the beetles by requirement (3) is at least partly addressed once brood begin emerging from earlier-attacked trees since these brood beetles fly to the spot head and contribute to sustaining fresh mass attacks and uninterrupted presence of the aggregation attractant (Gara, 1967). Additionally, parent adult beetles typically reemerge and contribute to new mass attacks. 
Switching will be prevented and infestations will collapse (or never become initiated) if the above three conditions are not met, and elimination of one or more of these conditions is the biological basis for methods currently being applied for direct control of $D$. frontalis, which are aimed primarily at stopping spot growth. It has been demonstrated that removal of the currently mass-attacked trees (ie, the source of aggregation pheromone) within an infestation can often be a sufficient measure to stop spot growth (Clarke et al., 1999; Cronin et al., 1999; Gara, 1967). In addition, the recommended cutting of a "buffer" of unattacked trees in advance of the massattacked trees increases the distance of the nearest suitable host tree to the natural source of $D$. frontalis attractant. If infested trees with beetle brood are removed from the site after cutting, this reduces the local densities of beetles available to sustain mass attacks.

\section{GEOGRAPHIC VARIATION}

Intraspecific geographic variation in the pheromone composition of bark beetles is common and may occur across very small distances (Lanier and Burkholder, 1974; Lanier et al., 1972; Miller et al., 1989; Seybold, 1993). Cross-mating experiments among $D$. frontalis populations from the southeastern United States, Arizona, and Nuevo Leon, Mexico as well as from Texas and Honduras (Lanier et al., 1988; Vité et al., 1974) suggest the lack of post-mating reproductive isolation mechanisms among these populations. Furthermore, consistency in seminal rod morphology and karyotype further supports the validity of $D$. frontalis as a single species throughout its extensive range (Armendáriz-Toledano et al., 2014; Lanier et al., 1988). However, there is evidence of some variation in pheromone production within the species. Newly emergent males in Honduras and Chiapas, Mexico, and Arizona contain substantially larger quantities of endobrevicomin than beetles sampled in Texas or Mississippi (Pureswaran et al., 2008a; Sullivan et al., 2007b, 2012; Vité et al., 1974). The biological implications of this difference are unknown. A study which examined volatiles from emergent male and female $D$. frontalis discovered some quantitative differences in pheromone component production by beetles in North Carolina, South Carolina, and Texas (Grosman et al., 1997). Nevertheless, in general the pheromone component blends produced by $D$. frontalis are remarkably consistent across its vast range (Fig. 9) and, at least for females, are distinguished from those of sibling species that have been studied (NiñoDomínguez et al., 2015a; Pureswaran et al., 2008a; Renwick et al., 1975; Sullivan et al., 2012; Vité et al., 1974). 
A

A

Male: Mississippi, United States
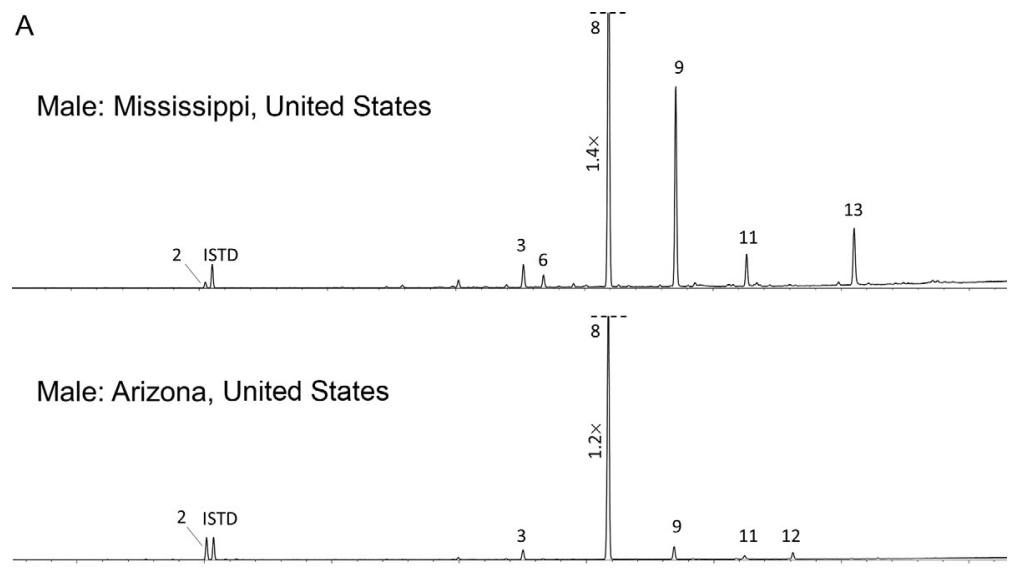

Male: Chiapas, Mexico

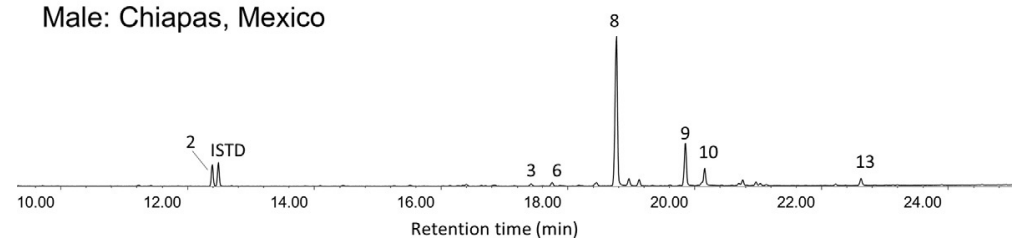

B

Female: Mississippi, United States

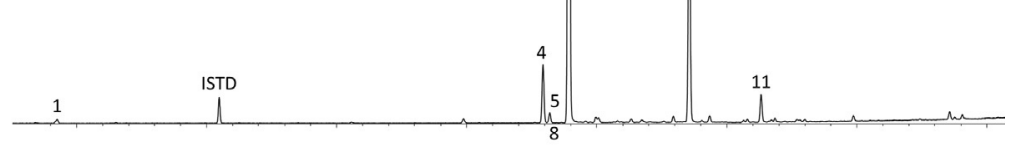

Female: Arizona, United States
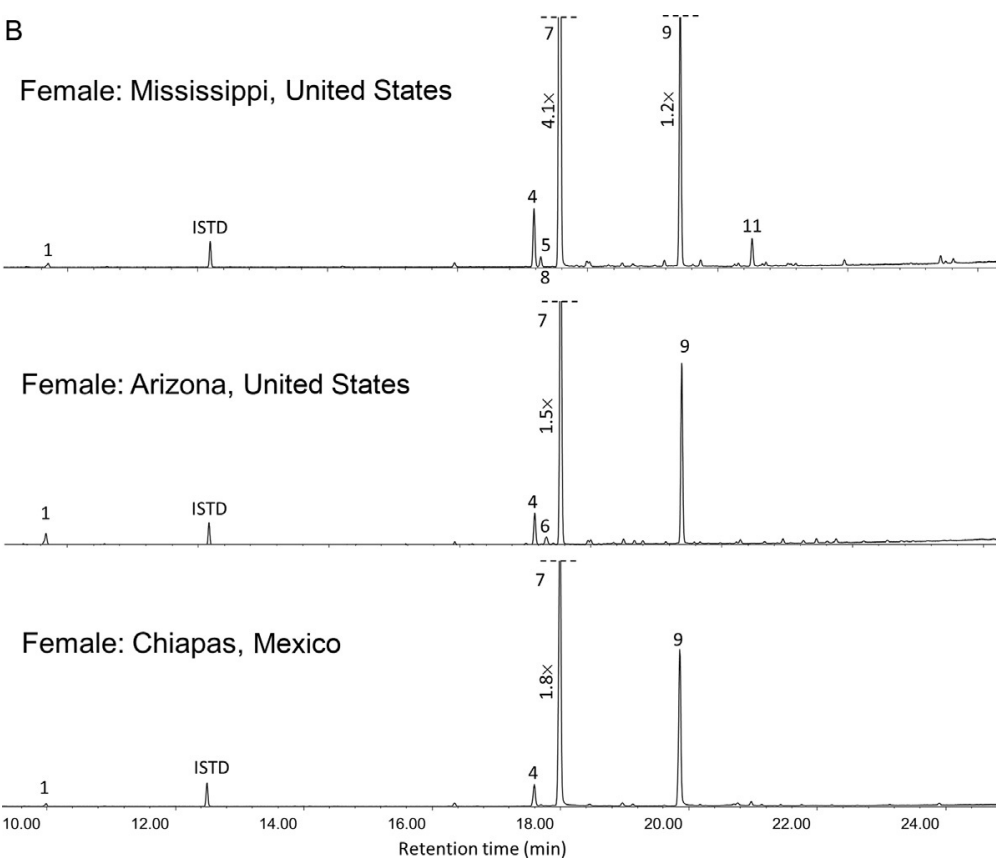

Fig. 9 See legend on opposite page. 
In the only experiment in which geographic variation in $D$. frontalis pheromone responses was directly investigated, D. frontalis in a walking olfactometer responded more frequently to odours from logs artificially infested by beetles from the same population than distant populations, with these populations being derived from Georgia, Texas, and Virginia, United States (Berisford et al., 1990). However, the chemical composition of the volatiles released by these infested logs was not examined for regional differences. In general, responses by $D$. frontalis to semiochemical lures appear to be similar wherever in the range of the insect that trapping experiments have been performed. For example, in both Chiapas, Mexico, and in Mississippi, United States (in trapping experiments performed in portions of the forest located away from infestations), $D$. frontalis were strongly attracted to the combination of frontalin and turpentine, and this combination was synergized by the addition of endo-brevicomin but unattractive without frontalin (Moreno et al., 2008; Niño-Domínguez et al., 2015a; Sullivan et al., 2007b). Tests performed near Dendroctonus infestations in Honduras indicated $D$. frontalis attraction to frontalin and host odours but inhibition by endo-brevicomin (Vité et al., 1974); the same outcome was observed in studies performed in D. frontalis infestations in the southern United States (Payne et al., 1978a; Salom et al., 1992b; Sullivan et al., 2011). It is possible that the "reversing" of the attraction-enhancing effects of endo-brevicomin lures associated with close proximity of infested trees or other sources of endo-brevicomin is consistent between regions.

\section{$>$ 7. MATE FINDING AND SELECTION \\ 7.1 Aggregation vs Sex Pheromones}

Frontalin appears to be the critical pheromone component which attracts alighted male $D$. frontalis to a gallery entrance occupied by a solitary female (Niño-Domínguez et al., 2015b). When an odour blend associated with solitary female entrances (ie, frontalin, trans-verbenol, and $\alpha$-pinene) was

Fig. 9 Representative total ion chromatogram traces of static headspace aeration (18 h) plus hindgut contents for newly emerged male (A) and female (B) $D$. frontalis collected from three distant populations. Each trace is the analysis from a single insect, and the sample chosen for presentation here was selected randomly from a pool of sample analyses. Compounds are (1) frontalin, (2) endo-brevicomin, (3) myrtenal, (4) cis-verbenol, (5) trans-pinocarveol, (6) acetophenone, (7) trans-verbenol, (8) verbenone, (9) myrtenol, (10) 1-phenylethanol, (11) trans-myrtanol, (12) 2-phenylethanol, (13) unknown-likely a dioxygenated monoterpene. "ISTD" is the internal standard (heptyl acetate at $175 \mathrm{ng} /$ sample). Procedures as Sullivan et al. (2012). 
released from an artificial gallery entrance covered by a screen (Ryker, 1988), males were arrested above the screen and stridulated producing the "courtship chirp" which they also produce when digging through frass at the gallery entrance of a solitary female (Rudinsky and Michael, 1974). Hence compounds in the female portion of the aggregation-stimulating blend also release male behaviours associated specifically with courtship and pairing. Furthermore, when the female-associated blend was combined with the male pheromone components endo-brevicomin (released over a wide range of doses) or verbenone (at high concentrations), males were less frequently arrested at the entrance and produced a "rivalry chirp" associated with male-male encounters (Rudinsky, 1973b; Rudinsky et al., 1974). Presumably these pheromone components signal the presence of a male in the gallery (Rudinsky and Michael, 1974). The contrast between the consistent inhibitory effects of endo-brevicomin in laboratory trials with walking male D. frontalis (Niño-Domínguez et al., 2015a; Rudinsky et al., 1974) and the attractive effects of endo-brevicomin on flying males (ie, at low doses and away from infestations) indicates that the signal may have a different, context-dependent meaning during search for either an active infestation or a host tree (where endo-brevicomin could signal that successful colonization by conspecifics is occurring) or a mate (in which case it indicates a prospective mate is already paired).

\subsection{Pheromones in Reproductive Isolation}

Little research has been done on the role of $D$. frontalis pheromones in mediating reproductive isolation from closely related species, although several such species may occupy the same portions of hosts (ie, exist in syntopy), utilize the same aggregation pheromone components, and be capable of pairing in the laboratory (Armendáriz-Toledano et al., 2014, 2015; Davis and Hofstetter, 2009; Hofstetter et al., 2008, 2012; Lanier et al., 1988; Moser et al., 2005; Niño-Domínguez et al., 2015a; Sullivan et al., 2012). In olfactometer studies of $D$. frontalis and its sibling $D$. mesoamericanus which jointly colonize the same hosts in the Central American region, it was found that males could readily distinguish odours of conspecific and heterospecific female gallery entrances, and ipsdienol and endo-brevicomin (compounds produced by $D$. mesoamericanus but not $D$. frontalis females) were identified as the species-specific cues that mediated this discrimination (NiñoDomínguez et al., 2015a).

The seemingly small amount of variation in pheromone composition and production across widely separated populations of $D$. frontalis contrasts 
with a high degree of individual variation in pheromone production within populations (Renwick and Vité, 1970), such that the coefficient of variation for female-produced pheromone components including frontalin and transverbenol typically exceeds 100\% (Pureswaran et al., 2007). It is possible that aggregation behaviour and communal production of pheromones decreases the importance of any single insect's contribution to the aggregation pheromone plume and thus to successful mass attack. Thus natural selection may be limited in its influence on the composition of the aggregation pheromone (Pureswaran et al., 2007). However, male (and possibly female) discrimination and selection of mates at gallery entrances on the basis of pheromone composition should not be subject to the diluting effects of communal production of aggregation pheromones, and thus there may be stronger selection on composition of the pheromone blend in its function as a sex pheromone than as an aggregation pheromone.

A significant degree of cross-attraction between $D$. frontalis and syntopic species of Dendroctonus to their respective aggregation pheromones (Armendáriz-Toledano et al., 2014; Hofstetter et al., 2008, 2012; NiñoDomínguez et al., 2015a) would seem to be at odds with pressures to maintain reproductive isolation between such species. However, it is likely that mass attacks by multiple-species may be more successful than single-species attacks if a single species is at insufficient numbers to mass attack a tree (Økland et al., 2009, 2011). Thus sharing of aggregation pheromone components may mediate such joint mass attacks and be a selective force that sustains overlap in pheromone composition among species (Symonds and Elgar, 2004). Differences in pheromone production (and other traits) in solitary females of differing species would confer reproductive isolation once beetles had landed.

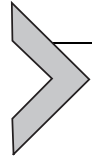

\section{SEMIOCHEMICAL INTERACTIONS WITH ARTHROPOD ASSOCIATES}

\subsection{Interspecific Pheromone Interactions with Other Bark Beetles}

Within the southeastern United States, D. frontalis belongs to a guild of five species of bark beetles that may directly compete by infesting the same or adjacent tissues of the same pines (Coulson et al., 1986; Flamm et al., 1993; Nebeker, 2011). The "southern pine bark beetle guild" includes Ips avulsus (Eichhoff), I. grandicollis (Eichhoff), I. calligraphus (Germar), and $D$. terebrans in addition to $D$. frontalis. Each produces a unique aggregation/sex pheromone blend that functions in attracting mates and possibly 
in aggregating conspecifics for mass attack (Smith et al., 1993). The species tend to partition the host tree by colonizing different portions of the bole but there is nonetheless substantial niche overlap and competition among them (Paine et al., 1981). Within established, growing D. frontalis infestations, D. frontalis represents the pioneer species that selects trees and initiates mass attack on new trees; other members of the guild typically follow (Stephen, 2011). However, during non-epidemic periods or initiation of infestations (ie, during first attacks on an isolated, susceptible tree) the order of arrival of species within the guild and their relative abundance may vary (Birch et al., 1980; Coulson et al., 1986; Flamm et al., 1993; Paine et al., 1981; Svihra et al., 1980). One might expect pheromones produced by each member of such a guild to mediate at least one of three potential interspecific responses: (1) synchronized, multispecies mass attack in which species are simultaneously engaged in overcoming host defence, (2) sequential species attack due to species that "easvesdrop" on pheromones of the earlierarriving, mass-attacking species and then colonize only after host defences are rendered sufficiently neutralized, (3) cross-inhibition to reduce competitive interactions through host partitioning. Given the seeming fitness benefits of any or all of the three responses above, it is surprising both that (1) Dendroctonus frontalis shows no attraction to the pheromone blends associated with any of the Ips species in the southern guild or to Ips more generally (Birch et al., 1980; Hofstetter et al., 2012; Svihra et al., 1980) and (2) the other Ips species display no attraction to D. frontalis with the possible exception of a weak positive response by I. grandicollis (Svihra et al., 1980). Crossinhibition of the Ips spp. with D. frontalis is also limited. Flying D. frontalis appeared to be less attracted to logs infested simultaneously by both conspecific females and I. grandicollis males, and the paper's authors argued that this response could relate to interspecific bole partitioning, with I. grandicollis infesting lower branches and D. frontalis infesting the bole (Svihra et al., 1980). In both laboratory and field experiments in Chiapas, Mexico, the Ips pheromone component ipsdienol strongly inhibited responses by D. frontalis to attractant (Niño-Domínguez et al., 2015a,b), although in Chiapas ipsdienol is produced by potentially sympatric D. mesoamericanus and possibly male D. frontalis (Sullivan et al., 2012). As discussed earlier, responses to mutually produced, attractive pheromone components by $D$. terebrans and D. frontalis could potentially mediate cross-attraction and joint host colonization (Smith et al., 1990), but this possibility has not been sufficiently examined. Additionally, given evidence for cross-attraction between $D$. frontalis and D. brevicomis (Hofstetter et al., 2012; Pureswaran et al., 2008a) and 
between D. frontalis and D. mesoamericanus (Niño-Domínguez et al., 2015a), it would appear that for $D$. frontalis that bark beetle cross-attraction may be limited to congeners.

\subsection{Exploitation of $D$. frontalis Pheromone by Predators and Parasitoids}

Natural enemies have evolved attractive responses to the aggregation pheromones of their prey, presumably because these cues are highly reliable and detectable indicators of prey presence (Steidle and van Loon, 2002; Vet and Dicke, 1992). Apparency to predators is perhaps an unavoidable cost of the use of aggregation pheromones by aggressive bark beetle species during the colonization of trees (Raffa and Dahlsten, 1995; Raffa and Klepzig, 1989). The clerid beetle, Thanasimus dubius (Fabricius), is an abundant and highly visible predator of $D$. frontalis populations in the southeastern and eastern United States, and evidence indicates that it may be an important mortality agent (Moore, 1972; Reeve, 1997). It captures and consumes D. frontalis as they land on the bark of host trees undergoing mass attack, and its larvae, developing from eggs laid within bark crevices, move throughout the gallery system of $D$. frontalis and consume beetle brood (Thatcher and Pickard, 1966). There are obvious fitness benefits accrued by $T$. dubius in arriving precisely when D. frontalis are landing (Camors and Payne, 1973; Dixon and Payne, 1979a, 1980; Thatcher and Pickard, 1966) hence their attraction to the $D$. frontalis aggregation attractant achieves this purpose well. Thanasimus dubius apparently locate $D$. frontalis-attacked trees primarily by responding to frontalin and host monoterpenes (Vité and Williamson, 1970). In experimental trials the host component could be presented as either $\alpha$-pinene or distilled pine resin (Billings, 1985; Billings and Cameron, 1984; Costa and Reeve, 2011; Staeben et al., 2015; Vité and Williamson, 1970). Thanasimus dubius may sometimes be observed congregating on pines where $D$. frontalis brood beetles are emerging (Clarke and Menard, 2006), presumably because the emergent $D$. frontalis contain their aggregation pheromone (Pureswaran et al., 2007) and are apparently "leaking" it in sufficient quantities during emergence to attract this predator. Thanasimus dubius' response is more strongly synergized by higher concentrations of host odours (eg, $\mathrm{g} / \mathrm{d}$ levels from trap lures) in parallel with their D. frontalis prey (Billings, 1985, author's unpublished data). However, T. dubius appears to respond solely to the (-)-enantiomer of frontalin, whereas its prey $D$. frontalis responds to both enantiomers but produces predominantly (-) (ie, 85-95\%); moreover T. dubius may entirely lack the 
capacity to sense the (+)-enantiomer (Payne et al., 1984). These authors suggested that $T$. dubius may be a semiochemical specialist on $D$. frontalis. This idea is supported by the generally stronger attraction by $T$. dubius to frontalin than pheromone components of its alternative Ips prey, as well as strong responses to frontalin by $T$. dubius populations located outside the range of $D$. frontalis or any other known frontalin-producing prey species (Aukema and Raffa, 2005; Reeve et al., 2009).

Investigations of predator-prey interactions in other bark beetle systems have suggested that disparities between the maximally attractive semiochemical blends for bark beetle prey and their predators may provide a "chemically mediated predator free space" that may have resulted from directional selection by predators on the pheromone composition of their prey (Aukema and Raffa, 2000; Aukema et al., 2000; Dahlsten et al., 2004). Such semiochemical-based predator escape may involve differing predator/prey responses to components of the prey's aggregation pheromone (Dahlsten et al., 2004; Raffa and Klepzig, 1989) as well as the host tree-produced pheromone synergists (Erbilgin and Raffa, 2001). In fact, T. dubius and their D. frontalis prey are not maximally attracted to the same semiochemical blend, suggesting a less-than-ideal "search image" is used by $T$. dubius in seeking its $D$. frontalis prey. Despite the strongly synergistic effect of aggregation pheromone component endo-brevicomin on attraction of D. frontalis to baited traps (Sullivan et al., 2007b; Vité et al., 1985) and thus its being a presumable indicator of localized concentrations of $D$. frontalis, endo-brevicomin does not appear to enhance attraction of $T$. dubius (Mizell et al., 1984; Richerson and Payne, 1979; Salom et al., 1992b), and neither does the exo-isomer which likewise can function as an attractive synergist for D. frontalis (Pureswaran et al., 2008a). A similar situation occurs with the aggregation pheromone component lanierone in Ips pini (Say) which is a potent attractive synergist for conspecifics but has no effect on attraction of predators including T. dubius (Aukema and Raffa, 2000). Lack of response by $D$. frontalis-seeking $T$. dubius to endo-brevicomin may be due to the fact that endo-brevicomin does not direct landings by $D$. frontalis to its point of release [whereas frontalin and host odours apparently have this effect; (Sullivan and Mori, 2009)], and furthermore since it is a "multifunctional" pheromone component it can have inhibitory effects on D. frontalis at high concentrations (Sullivan et al., 2011). As such, its presence might not increase the odds of a $T$. dubius encountering a prey insect at least at close range. A mismatch of attractive cues also occurs due to a preference by $D$. frontalis for the $(+)$-enantiomer of the synergistic host monoterpene $\alpha$-pinene when combined with its aggregation pheromone, whereas 
no preference for enantiomers occurs in T. dubius (Staeben et al., 2015). As the host species of pine utilized by $D$. frontalis vary in the enantiomeric composition of $\alpha$-pinene, presumably $D$. frontalis might enhance escape from predation in preferential attack of trees with relatively high $(+)-\alpha$-pinene composition, such as Pinus taeda L. which is a preferred host for D. frontalis (Phillips et al., 1999). Another abundant predator apparently attracted to the pheromone components of $D$. frontalis is Medetera bistriata (Diptera: Dolichopodidae), which lay their eggs in the newly created beetle galleries such that their hatching larvae can feed on the early brood stages of their host (Dixon and Payne, 1979b).

In contrast to the predators, the guild of hymenopteran parasitoids of D. frontalis (which include at least eight common species predominantly in the families Braconidae and Pteromalidae) generally do not respond to the beetles' aggregation pheromone components (Dixon and Payne, 1979b; Payne, 1989). Pheromone release by the mass-attacking parent $D$. frontalis is finished well before the preferred host life stages (late-instar larvae and pupae within the bark) for the parasitoids are available (Berisford, 2011), hence the pheromones are not suitable cues. Rather, at least some of the parasitoid species appear to be attracted to as-yet unidentified olfactory cues (which likely include oxygenated monoterpenes) associated specifically with bark infested with their preferred host life stages (Sullivan et al., 1997, 2000).

\section{EXPLOITATION OF SEMIOCHEMISTRY IN MANAGEMENT OF D. FRONTALIS}

Not surprisingly, research on the semiochemical system of this serious pest has been driven largely by the desire to develop tools that can lessen its economic and environmental impact. With the first successful syntheses of attractant and attraction-inhibiting semiochemicals, efforts were initiated immediately at using each to manipulate movement of D. frontalis populations to disrupt their capacity to congregate on and kill trees (Vité, 1970; Vité and Francke, 1976). Despite the diversity of ways researchers have attempted to use attractants and inhibitors to prevent or reduce tree mortality from $D$. frontalis, no semiochemical-based technology is currently in common use for stand or tree protection. The research efforts are detailed in this section. Greater success can perhaps be claimed with regard of the use of attractants to monitor population fluctuations and make forecasts regarding outbreaks; this technology is in wide use and is a key component of state and federal efforts to address $D$. frontalis on an annual basis. 


\subsection{Population Monitoring and Prediction}

Within the southeastern United States, attractant-baited traps are deployed by state and federal cooperators each spring (at bud-break of dogwood, Cornus florida L., which coincides approximately with $D$. frontalis' spring flight) and are used for making forecasts of the likelihood of $D$. frontalis outbreaks and their severity for the coming summer (Billings, 1988, 2011). Data on both the average daily catches of $D$. frontalis per trap as well as ratios of catches of $D$. frontalis to $T$. dubius are data used in a model which forecasts outbreaks with a demonstrated 60-80\% reliability (Billings, 2011; Billings and Upton, 2010). These forecasts, which are completed by early summer, are then used by regional land managers in planning activities (eg, scheduling flights by reconnaissance aircraft) and in coordinating monetary and human resources necessary for beetle management activities expected during the coming months. Since the beginning of the trapping programme during the 1980s, the attractant has consisted of frontalin (4-8 $\mathrm{mg} / \mathrm{d})$ released with a high rate (ie, $1-10 \mathrm{~g} / \mathrm{d}$ ) of host odours. Initially, the host odour component consisted of turpentine distilled from $P$. taeda, but due to the loss of commercial sources of suitable turpentine during the 2000s, the host component was switched to a synthetic blend of $\alpha$ - and $\beta$-pinene. Recent efforts at enhancing the existing monitoring/forecasting programme have considered a range of modifications of methodology including revision of the composition of the trap lure (including the possible inclusion of endo-brevicomin to enhance sensitivity) and addition of further monitoring periods during the year (Billings, 2011). The beetle-produced (+)-enantiomer of endobrevicomin and the racemate (at a doubled dose) appear to be similarly potent attractive synergists (Sullivan and Mori 2009), and thus the far less expensive racemate is recommended for inclusion in enhanced monitoring lures.

\subsection{Direct Control with Semiochemicals}

Development of semiochemical technology for direct control of $D$. frontalis during epidemics has focused on two spatial scales. (1) Stand level: suppression or reduction in the rate of growth of individual infestations and (2) Tree level: protection of individual, high value trees at risk of imminent mass attack due to their proximity to growing infestations (Strom and Clarke, 2011). Infestations are discovered by means of aerial surveys conducted systematically in the late spring through summer (Billings, 2011). Locations of trees with yellowing foliage are noted and then ground checked to 
determine whether the mortality agent is $D$. frontalis and whether the infestations are "active" (ie, continuing to accumulate freshly attacked trees) (Billings, 2011). Because foliage of mass-attacked, beetle-killed trees often requires weeks before a change in foliage colour is readily detected from the air (Clarke, 2001), spots are often large and growing quickly when first detected (Billings and Kibbe, 1978). Currently, two main techniques are recommended for infestation suppression: "cut-and-remove" and "cutand-leave" and both involve felling the trees currently undergoing attack at the head of the infestation along with a buffer strip of apparently unattacked trees located in the path of the growing infestation (Clarke and Nowak, 2010; Schowalter, 2012). In "cut-and-remove", all infested trees and the buffer are removed from the site thereby eliminating both the natural source of the aggregating pheromone and the major source of beetles that would be aggregated by it. This method is of course ideal from the standpoint that removed trees can often be salvaged and brood beetles that would otherwise disperse from infested trees and potentially do harm in the surrounding forest are eliminated (Cronin et al., 1999; Gara, 1967). Cut-and-leave is used when tree removal is not practical or economical; trees occupied by beetles and the buffer trees are all felled opposite the direction of spot growth but left in place. The apparent mechanism underlying this approach is the elimination (or interruption) of the aggregation pheromone plume that is produced by freshly attacked trees at the spot head, as this plume is critical for sustaining spot growth (Gara, 1967). Cut trees are reported to rapidly lose attractiveness (Vité and Crozier, 1968), however, other reports indicate that downed timber can sustain mass attacks (Moser, 1987). Emergent beetles from felled brood trees tend to disperse rather than regenerate a new head at the same location (Cronin et al., 1999), however the need for retreatment is more common for cut-and-leave than cut-and-remove (Clarke, 2001; Clarke and Billings, 2003). Nonetheless, the major mechanism underlying the success of both methods appears to be interruption of the beetles' semiochemical communication.

Extensive efforts to develop treatments involving synthetic semiochemical devices to control infestations of $D$. frontalis and protect trees occurred during the 1970s through the 1990s, but despite these efforts no method is yet operational or in common practice as of this writing. Four general approaches have been pursued: (1) direct elimination of beetles by attracting them to trees where they would attack but be unable to reproduce, (2) broadcast of attractants within an infestation to interrupt orientation toward host trees undergoing mass attack [comparable to pheromone 
disruption techniques applied in management of lepidopteran pests (Bartell, 2008; Carde and Minks, 1995; Witzgall et al., 2010)], (3) deployment of attractants at points within brood-containing areas of the infestation to reduce beetle densities at the spot head sufficiently to prevent mass attack and switching, and (4) application of attraction inhibitors or repellants to trees in advance of the growing infestation to arrest infestation growth or protect individual selected, trees.

Approach (1) involves attaching devices releasing attractant (frontalin and $\alpha$-pinene) to selected, healthy "trap trees" treated with herbicide (cacodylic acid, applied to axe wounds at the tree base) (Vité, 1970). Such trees are established in close proximity to brood trees within active or overwintering infestations, with the goal being to absorb emerging beetles onto the trap trees on which reproduction would be greatly reduced and brood production would become insufficient to support continued infestation growth. One notable advantage of this approach is that it allows initial ground check crews to treat trees and thereby take steps to arrest infestation growth immediately following infestation discovery and inspection. This "trap tree" method relies on several principles: (a) the lures should initiate attacks on the treated tree but, as attacks progress, pheromone released by the attacking beetles themselves should provide the "natural attractant" which would presumably be superior to that possible with synthetic lures and traps (Vité, 1970), (b) a higher number of "pitch-outs" should occur on the herbicide/attractant-treated trees which can cause direct mortality of parent adults (Copony and Morris, 1972), and (c) the offspring:parent ratio would be reduced below 1:1 causing local population decline (Copony and Morris, 1972; Coulson et al., 1973a). In one study, 60 of 65 treated infestations did not require retreatment (Copony and Morris, 1972). However, a large number of variables influence the method's potential for success (eg, beetle population densities, infestation size, time of year) (Coulson et al., 1973a,b), creating undesirable uncertainty and complexity with regard to practical implementation. Additionally, the need to poison large numbers of healthy trees makes the procedure unattractive to land managers (Wood, 1977).

Approach (2) was investigated in a single study in which rice soaked with frontalin and $\alpha$-pinene was spread over 10 ha of pine forest enclosing an active infestation (Vité et al., 1976). Counter to the expectation that hostseeking beetles would become dispersed and disoriented (Bartell, 2008), the treatment instead increased beetle landings on pines already undergoing attack while decreasing landings on oak trees previously baited with an 
attractant. Thus the net effect appeared to be an increase in aggregation and attack on pines within the infestation's head.

Approach (3) involves deploying attractant release devices (ie, frontalin and $\alpha$-pinene) onto trees within the interior of an active infestation that either contain brood (ie, larva through emerging adult stages) or are nonhosts. The goal is to attract brood adults emerging within the infestation [which are the beetles that make the greatest contribution to growth of an established infestation (Gara, 1967)] to trees that are unsuitable and located away from the head of the infestation and trees currently experiencing mass attack (Payne et al., 1985a,b; Richerson et al., 1980). In a three-replicate (and thus preliminary) study in two infestations, attractant-treatment of the infestation interior redistributed trap catches more evenly through the infestation, and it reduced landings on trees at the infestation head in a single trial (Payne and Richerson, 1979; Richerson et al., 1980). Additionally, no trees were mass attacked during the 3-6 days that the lures were in place, whereas infestation growth occurred both before and after treatment (Richerson et al., 1980). In an expanded study, reduction in infestation growth occurred invariably in 10 treated infestations in Georgia where beetles were at "endemic levels", whereas treatment of 15 infestations in Texas-where populations were "epidemic"-were not consistently effective (Payne et al., 1985a,b).

Approach (4) has received the most effort at development. Early studies with $D$. frontalis had indicated verbenone and brevicomin (both endo- and exo-isomers) could reduce responses by flying $D$. frontalis to attractant-baited traps (Payne et al., 1978a; Renwick and Vité, 1969; Vité and Renwick, 1971), which prompted attempts to use these compounds to protect trees at immediate risk (that is, trees located in the paths of growing infestations). In an attempt to protect individual trees, Richerson and Payne (1979) attached devices of either brevicomin (both exo- and endo-), verbenone, or their combination at 1 or $2 \mathrm{~m}$ intervals (four devices per height, encircling the bole) up to a height of $8-9 \mathrm{~m}$. Paired, adjacent trees were left untreated as controls. None of the treatments prevented mortality, although the treatments which included brevicomin reduced landing of $D$. frontalis by $74 \%$ (verbenone alone, however, with a total release of approximately $80 \mathrm{mg}$ / $\mathrm{d} /$ tree did not reduce landings) and there were few $D$. frontalis galleries in the brevicomin-treated trees (Payne and Richerson, 1979; Richerson and Payne, 1979). The brevicomin treatments however greatly increased the landings and attacks of the competing species $I$. avulsus, and this may have caused the mortality of the brevicomin-treated trees despite the reduced 
attacks by $D$. frontalis. The attraction of $I$. avulsus was unexpected given that in trapping studies $I$. avulsus has not demonstrated attraction to brevicomin or odours associated with D. frontalis pairs (Birch et al., 1980; Svihra, 1982). Since I. avulsus is less aggressive and cannot sustain infestation growth, it was proposed that, with reduced reproduction of $D$. frontalis both through semiochemical inhibition of attack and displacement by successfully competing I. avulsus, brevicomin/verbenone treatment would cause infestations to collapse (Payne and Richerson, 1985; Watterson et al., 1982). Thus brevicomin/verbenone treatment, although apparently not capable of saving trees actually receiving treatment, demonstrated potential to save other trees by accelerating spot collapse through semiochemical-induced "competitive replacement" (Payne and Richerson, 1985). This potential technology has not been developed further.

Deployment of releasers (soaked sponges enclosed in permeable plastic bags) of verbenone from all host pines undergoing mass attack as well as uninfested pines in a buffer up to $15 \mathrm{~m}$ width beyond the mass-attacked trees caused a fivefold reduction of additional attacked trees [relative to predictions of a spot growth model (Stephen and Lih, 1985)]. Furthermore, a ninefold reduction occurred when deployment of verbenone devices in the buffer was combined with cutting of infested trees at the spot head (Payne et al., 1992). In a different study, verbenone mixed with a liquid polymer that produced a controlled-release (average 160-200 mg/d/tree) was sprayed on infested and buffer trees (Payne and Billings, 1989). This treatment significantly reduced spot growth compared to model predictions, and combination of this verbenone application with removal of freshly attacked trees further improved treatment effectiveness. Infestations treated with releaser-packets of verbenone alone (with the numbers of packets adjusted to tree diametre) or combined with felling of freshly attacked trees were completely suppressed $69 \%$ and $86 \%$ of the time, respectively (compared to $90 \%$ success for cut-and-leave treatment) (Clarke et al., 1999). Given that verbenone has not been demonstrated to reduce landings on individual, infested trees (Richerson and Payne, 1979) nor alter the dispersion of beetles within infestations (Salom et al., 1995), the mechanism underlying the success of these "verbenone curtain" treatments is not clear, rendering it essentially impossible to make sufficiently informed attempts at method improvement.

On the other hand, brevicomin-incorporating treatments do not alter dispersion of flying beetles but rather appear to reduce $D$. frontalis landing rates on trees undergoing mass attack (Johnson and Coster, 1980; Payne 
et al., 1977). In the only study to examine infestation-wide effects of brevicomin, releasers of an endo/exo-brevicomin blend (36 total devices, $1.5 \mathrm{mg} / \mathrm{d} /$ device) were deployed from selected host trees within a grid that encompassed the active head of a growing $D$. frontalis infestation. The devices reduced landings of beetles on all host trees within the grid-treated or not-while having no effect on the densities of beetles flying in the infestation (Payne et al., 1977).

There are numerous additional $D$. frontalis-produced volatile compounds (most discussed above in the section on oxygenated monoterpenes) that have been shown to reduce beetle responses to attractant-baited traps, which suggests that these semiochemicals should be tested for potential in protecting trees or suppressing infestations (Sullivan, 2005; Sullivan et al., 2007a). One such D. frontalis attraction inhibitor, acetophenone, has demonstrated antiaggregant properties with other Dendroctonus spp. (Erbilgin et al., 2007a, 2008; Pureswaran and Borden, 2004) and has shown promise for inclusion in inhibitory semiochemical blends for managing the western and mountain pine beetles, D. brevicomis and D. ponderosae (Fettig et al., $2012 a, b, c)$. Acetophenone is clearly worthy of further investigation as a potential management semiochemical for $D$. frontalis.

The phenylpropanoid 4-allylanisole which naturally occurs in relatively small amounts within resin of host pines of $D$. frontalis was found to repel walking $D$. frontalis when it was applied to the walking surface, and furthermore devices releasing $>100 \mathrm{mg} / \mathrm{d}$ of 4-allylanisole significantly reduced D. frontalis attraction to traps baited with frontalin and $\alpha$-pinene (Hayes et al., 1994; Strom et al., 1999). Despite promising initial trials in which strings of releasers suspended along the tree bole appeared to prevent attacks on at-risk trees (Hayes et al., 1994; Strom et al., 1995), three different methods of deployment of 4-allylanisole (polymer/semiochemical-filled paintballs, microencapsulated semiochemical in a sprayable form, and vials attached directly to trees) releasing approximately $1-5 \mathrm{~g} / \mathrm{d} /$ tree failed to demonstrate efficacy in protecting trees challenged either with $D$. frontalis attractant lures or through weakening with application of a toxin (N-methyldithiocarbamate) (Strom et al., 2004).

Responses of $D$. frontalis to attractant-baited traps can be inhibited by certain volatiles associated with hardwoods and other non-host plants, as has been shown to occur within numerous other species of coniferinfesting bark beetles (Zhang and Schlyter, 2004). These "non-host volatiles" are believed to play an important role in mediating avoidance by coniferophagous bark beetles of habitats with few or no susceptible hosts 
and in preventing attack initiation on unsuitable trees (Byers et al., 2000; Zhang and Schlyter, 2003). Two such 6-carbon "green leaf alcohols", 1-hexanol and hexanal, both singly and in combination were found to significantly reduce $D$. frontalis responses to traps baited with frontalin and turpentine (Dickens et al., 1992). Likewise, a combination of non-host volatiles that included 1-hexanol, cis-3-hexen-1-ol, hexanal, and nonanal, in one of two tests significantly reduced catches of male $D$. frontalis in traps baited with frontalin and $\alpha$-pinene (Sullivan et al., 2007a). Shepherd and Sullivan (2013) collected volatiles from leaves and bark of eight different species within six genera of sympatric non-hosts for $D$. frontalis, and they observed GC-EAD responses to 28 compounds. These included 11 compounds not typically present in host pines (benzaldehyde, benzyl alcohol, guaiacol, heptanal, hexanal, 1-hexanol, (Z)-3-hexen-1-ol, (E)-2-hexenal, methyl salicylate, nonanal, and salilicylaldehyde). Of these (E)-2hexen-1-ol, and 1-hexanol had particularly low concentration thresholds of EAD response. The complete blend of 11 compounds significantly reduced trap responses of both sexes whereas subgroups within the blend (ie, the alcohols, aldehydes, green leaf volatiles, bark volatiles) did not. Data is still insufficient to assess the management potential of non-host volatiles for $D$. frontalis.

\section{CONCLUDING REMARKS}

There currently are no techniques adopted generally by foresters for managing $D$. frontalis with synthetic semiochemicals as biorational control agents. However, the fact that the mechanisms underlying the currently recommended procedures for direct control of D. frontalis (ie, cut-andleave, cut-and-remove) involve disruption of this insect's semiochemical communication suggests that manipulation of beetle behaviour through deployment of synthetic semiochemicals may nonetheless have potential for use in pest management. Thus chemical ecology may still hold the key for new management technologies that could eliminate current methods that require cutting of trees. Simultaneously, it has become increasingly apparent that the semiochemical system of $D$. frontalis is substantially more complex than originally envisioned by Renwick and Vité (1969), and insufficient basic science on the ecological roles of compounds such as verbenone, trans-verbenol, and endo-brevicomin assures that wellinformed decisions cannot be made with regard to development and enhancement of technology using these compounds. The list of naturally 
occurring volatile compounds that modify behaviours in Dendroctonus pine beetles is long and continues to increase (www.pherobase.com), and yet for many little is known about their ecology beyond what can be inferred from their ability to alter responses of beetles to traps.

\section{REFERENCES}

Anderson, N.H., Anderson, D.B., 1968. Ips bark beetle attacks and brood development on a lightning-struck pine in relation to its physiological decline. Fla. Entomol. 51, 23-30.

Andryszak, N.A., Payne, T.L., Billings, P.M., 1982. Effect of flight activity on laboratory response of the southern pine beetle to an attractant. J. Ga. Entomol. Soc. 17, 456-460.

Armendáriz-Toledano, F., Niño, A., Sullivan, B.T., Macías-Sámano, J., Víctor, J., Clarke, S.R., Zúñiga, G., 2014. Two species within Dendroctonus frontalis (Coleoptera: Curculionidae): evidence from morphological, karyological, molecular, and crossing studies. Ann. Entomol. Soc. Am. 107, 11-27.

Armendáriz-Toledano, F., Niño, A., Sullivan, B.T., Kirkendall, L.R., Zúñiga, G., 2015. A new species of bark beetle, Dendroctonus mesoamericanus sp. nov. (Curculionidae: Scolytinae), in southern Mexico and Central America. Ann. Entomol. Soc. Am. 108, 403-414.

Aukema, B.H., Raffa, K.F., 2000. Chemically mediated predator-free space: herbivores can synergize intraspecific communication without increasing risk of predation. J. Chem. Ecol. 26, 1923-1939.

Aukema, B.H., Raffa, K.F., 2005. Selective manipulation of predators using pheromones: responses to frontalin and ipsdienol pheromone components of bark beetles in the Great Lakes region. Agric. For. Entomol. 7, 193-200.

Aukema, B.H., Dahlsten, D.L., Raffa, K.F., 2000. Improved population monitoring of bark beetles and predators by incorporating disparate behavioral responses to semiochemicals. Environ. Entomol. 29, 618-629.

Ayres, M.P., Martinson, S.J., Friedenberg, N.A., 2011. Southern pine beetle ecology: populations within stands. In: Coulson, R.N., Klepzig, K.D. (Eds.), The Southern Pine Beetle II. In: General Technical Report SRS-140, USDA Forest Service Southern Research Station, Asheville, NC, pp. 75-89.

Bartell, R.J., 2008. Mechanisms of communication disruption by pheromone in the control of Lepidoptera: a review. Physiol. Entomol. 7, 353-364.

Bedard, W.D., Tilden, P.E., Lindahl Jr., K.Q., Wood, D.L., Rauch, P.A., 1980a. Effects of verbenone and trans-verbenol on the response of Dendroctonus brevicomis to natural and synthetic attractant in the field. J. Chem. Ecol. 6, 997-1013.

Bedard, W.D., Wood, D.L., Tilden, P.E., Lindahl Jr., K.Q., Silverstein, R.M., Rodin, J.O., 1980b. Field responses of the western pine beetle and one of its predators to host- and beetle-produced compounds. J. Chem. Ecol. 6, 625-641.

Bentz, B.J., Powell, J.A., Logan, J.A., 1996. Localized spatial and temporal attack dynamics of the mountain pine beetle in lodgepole pine. USDA Forest Service, Intermountain Research Station INT-RP-494, 10 pp.

Bennett, R.B., Borden, J.H., 1971. Flight arrestment of tethered Dendroctonus pseudotsugae and Trypodendron lineatum (Coleoptera: Scolytidae) in response to olfactory stimuli. Ann. Entomol. Soc. Am. 64, 1273-1286.

Berisford, C.W., 2011. Parasitoids of the southern pine beetle. In: Coulson, R.N., Klepzig, K.D. (Eds.), Southern Pine Beetle II. In: General Technical Report SRS-140 USDA Forest Service Southern Research Station, Asheville, NC, pp. 129-139. 
Berisford, C.W., Payne, T.L., Berisford, Y.C., 1990. Geographical variation in response of southern pine beetle (Coleoptera: Scolytidae) to aggregating pheromones in laboratory bioassays. Environ. Entomol. 19, 1671-1674.

Billings, R.F., 1985. Southern pine bark beetles and associated insects: effects of rapidly-released host volatiles on response to aggregation pheromones. J. Appl. Entomol. 99, 483-491.

Billings, R.F., 1988. Forecasting southern pine beetle infestation trends with pheromone traps. In: Payne, T.L., Saarenmaa, H. (Eds.), Integrated Control of Scolytid Bark Beetles: Proceedings of Symposium. IUFRO Working Party and XVII International Congress of Entomology, Vancouver, BC, pp. 295-306.

Billings, R.F., 2011. Aerial detection, ground evaluation, and monitoring of the southern pine beetle: state perspectives. In: Coulson, R.N., Klepzig, K.D. (Eds.), Southern Pine Beetle II. In: General Technical Report SRS-140, USDA Forest Service Southern Research Station, Asheville, NC, pp. 245-261.

Billings, R.F., Cameron, R.S., 1984. Kairomonal responses of Coleoptera, Monochamus titillator (Cerambycidae), Thanasimus dubius (Cleridae), and Temnochila virescens (Trogositidae), to behavioral chemicals of southern pine bark beetles (Coleoptera: Scolytidae). Environ. Entomol. 13, 1542-1548.

Billings, R.F., Kibbe, C.A., 1978. Seasonal relationships between southern pine beetle brood development and loblolly pine foliage color in east Texas. Southwest. Entomol. 3, 89-96.

Billings, R.F., Upton, W.W., 2010. A methodology for assessing annual risk of southern pine beetle outbreaks across the southern region using pheromone traps. In: Pye, J.M., Rauscher, H.M., Sands, Y., Lee, D.C., Beatty, J.S. (Eds.), Advances in Threat Assessment and Their Application to Forest and Rangeland Management. U.S. Department of Agriculture, Forest Service, Pacific Northwest and Southern Research Stations Gen. Tech. Rep. PNW-GTR-802, Portland, OR, pp. 73-85.

Birch, M.C., Svihra, P., Paine, T.D., Miller, J.C., 1980. Influence of chemically mediated behavior on host tree colonization by four cohabitating species of bark beetle. J. Chem. Ecol. 6, 395-414.

Birt, A., 2011. Population dynamics of southern pine beetle in forest landscapes. In: Coulson, R.N., Klepzig, K.D. (Eds.), Southern Pine Beetle II. In: General Technical Report SRS-140, USDA Forest Service Southern Research Station, Asheville, NC, pp. 91-108.

Blanche, C.A., Hodges, J.D., Nebeker, T.E., 1985. Changes in bark beetle susceptibility indicators in a lightning-struck loblolly pine. Can. J. For. Res. 15, 397-399.

Blomquist, G.J., Figueroa-Teran, R., Aw, M., Song, M.M., Gorzalski, A., Abbott, N.L., Chang, E., Tittiger, C., 2010. Pheromone production in bark beetles. Insect Biochem. Mol. Biol. 40, 699-712.

Borden, J.H., 1997. Disruption of semiochemical-mediated aggregation in bark beetles. In: Cardé, R.T., Minks, A.K. (Eds.), Insect Pheromone Research: New Directions. Chapman and Hall, New York, pp. 421-438.

Borden, J.H., Hunt, D.W.A., Miller, D.R., Slesslor, K.N., 1986. Orientation in forest Coleoptera: an uncertain outcome of responses by individual beetles to variable stimuli. In: Payne, T.L., Birch, M.C., Kennedy, C.E.J. (Eds.), Mechanisms in Insect Olfaction. Clarendon Press, Oxford, pp. 97-109.

Borden, J.H., Chong, L.J., Lindgren, B.S., 1990. Redundancy in the semiochemical message required to induce attack on lodgepole pines by the mountain pine beetle, Dendroctonus ponderosae Hopkins (Coleoptera: Scolytidae). Can. Entomol. 122, 769-777.

Brand, J.M., Bracke, J.W., Markovetz, A.J., Wood, D.L., Browne, L.L., 1975. Production of verbenol pheromone by a bacterium isolated from bark beetles. Nature 254, 136-137.

Brand, J.M., Bracke, J.W., Britton, L.N., Markovetz, A.J., Barras, S.J., 1976. Bark beetle pheromones: production of verbenone by a mycangial fungus of Dendroctonus frontalis. J. Chem. Ecol. 2, 195-199. 
Brand, J.M., Schultz, J., Barras, S.J., Edson, L.J., Payne, T.L., Hedden, R.L., 1977. Barkbeetle pheromones-enhancement of Dendroctonus frontalis (Coleoptera: Scolytidae) aggregation pheromone by yeast metabolites in laboratory bioassays. J. Chem. Ecol. 3, 657-666.

Bridges, J.R., 1982. Effects of juvenile hormone on pheromone synthesis in Dendroctonus frontalis. Environ. Entomol. 11, 417-420.

Browne, L.E., Wood, D.L., Bedard, W.D., Silverstein, R.M., West, J.R., 1979. Quantitative estimates of the western pine beetle attractive pheromone components, exobrevicomin, frontalin, and myrcene in nature. J. Chem. Ecol. 5, 397-414.

Bunt, W.D., Coster, J.E., Johnson, P.C., 1980. Behavior of the southern pine beetle on the bark of host trees during mass attack. Ann. Entomol. Soc. Am. 73, 647-652.

Byers, J.A., 1983. Sex-specific responses to aggregation pheromone: regulation of colonization density in the bark beetle Ips paraconfusus. J. Chem. Ecol. 9, 129-142.

Byers, J.A., 1987. Interactions of pheromone component odor plumes of western pine beetle. J. Chem. Ecol. 13, 2143-2157.

Byers, J.A., 1989a. Behavioral mechanisms involved in reducing competition in bark beetles. Holarct. Ecol. 12, 466-476.

Byers, J.A., 1989b. Chemical ecology of bark beetles. Experientia 45, 271-283.

Byers, J.A., 1996. An encounter rate model of bark beetle populations searching at random for susceptible host trees. Ecol. Model. 91, 57-66.

Byers, J.A., Wood, D.L., Craig, J., Hendry, L.B., 1984. Attractive and inhibitory pheromones produced in the bark beetle, Dendroctonus brevicomis, during host colonization: regulation of inter- and intraspecific competition. J. Chem. Ecol. 10, 861-877.

Byers, J.A., Zhang, Q.H., Birgersson, G., 2000. Strategies of a bark beetle, Pityogenes bidentatus, in an olfactory landscape. Naturwissenschaften 87, 503-507.

Camors Jr., F.B., Payne, T.L., 1973. Sequence of arrival of entomophagous insects to trees infested with the southern pine beetle. Environ. Entomol. 2, 267-270.

Carde, R.T., Minks, A.K., 1995. Control of moth pests by mating disruption: successes and constraints. Ann. Rev. Entomol. 40, 559-585.

Chatelain, M.P., Schenk, J.A., 1984. Evaluation of frontalin and exo-brevicomin as kairomones to control mountain pine beetle (Coleoptera: Scolytidae) in lodgepole pine. Environ. Entomol. 13, 1666-1674.

Clarke, S.R., 2001. Review of the operational IPM program for the southern pine beetle. Integr. Pest Manag. Rev. 6, 293-301.

Clarke, S., 2012. Implications of population phases on the integrated pest management of the southern pine beetle, Dendroctonus frontalis. J. Integr. Pest Manage 3, 1-9.

Clarke, S.R., Billings, R.F., 2003. Analysis of the southern pine beetle suppression program on the national forests in Texas in the 1990s. So. J. Appl. For. 27, 122-129.

Clarke, S.R., Menard, R.D., 2006. Predation of an ambrosia beetle (Coleoptera: Platypodidae) by a checkered beetle (Coleoptera: Cleridae) congregating on pines containing brood adult southern pine beetles (Coleoptera: Curculionidae). J. Entomol. Sci. 41, 257.

Clarke, S.R., Nowak, J.T., 2010. Southern Pine Beetle. USDA Forest Service Forest Insect and Disease Leaflet 49. USDA Forest Service, Pacific Northwest Region, Portland, Oregon.

Clarke, S.R., Salom, S.M., Billings, R.F., Berisford, C.W., Upton, W.W., McClellan, Q.C., Dalusky, M.J., 1999. A Scentsible approach to controlling southern pine beetles. J. For. 97, 26-31.

Cook, S.P., Hain, F.P., 1988. Toxicity of host monoterpenes to Dendroctonus frontalis and Ips calligraphus (Coleoptera: Scolytidae). J. Entomol. Sci. 23, 287-292.

Copony, J.A., Morris, C.L., 1972. Southern pine beetle suppression with frontalure and cacodylic acid treatments. J. Econ. Entomol. 65, 754-757. 
Costa, A., Reeve, J.D., 2011. Upwind flight response of the bark beetle predator Thanasimus dubius towards olfactory and visual cues in a wind tunnel. Agric. For. Entomol. 13, 283-290.

Coster, J.E., Vité, J.P., 1972. Effects of feeding and mating on pheromone release in the southern pine beetle. Ann. Entomol. Soc. Am. 65, 263-266.

Coster, J.E., Payne, T.L., Hart, E.R., Edson, L.J., 1977. Aggregation of the southern pine beetle in response to attractive host trees. Environ. Entomol. 6, 725-731.

Coster, J.E., Hicks Jr., R.R., Watterston, K.G., 1978. Directional spread of southern pine beetle (Coleoptera: Scolytidae) infestations in East Texas. J. Ga. Entomol. Soc. 13, 315-321.

Coulson, R.N., 1979. Population dynamics of bark beetles. Ann. Rev. Entomol. 24, 417-447.

Coulson, R.N., Oliveria, F.L., Payne, T.L., Houseweart, M.W., 1973a. Variables associated with use of frontalure and cacodylic acid in suppression of the southern pine beetle. 2 . Brood reduction in trees treated with cacodylic acid. J. Econ. Entomol. 66, 897-899.

Coulson, R.N., Oliveria, F.L., Payne, T.L., Houseweart, M.W., 1973b. Variables associated with use of frontalure and cacodylic acid in supression of the southern pine beetle. 1. Factors influencing manipulation to prescribed trap trees. J. Econ. Entomol. 66, 893-896.

Coulson, R.N., Hennier, P.B., Flamm, R.O., Rykiel, E.J., Hu, L.C., Payne, T.L., 1983. The role of lightning in the epidemiology of the southern pine beetle. Z. Angew. Entomol. 96, 182-193.

Coulson, R.N., Flamm, R.O., Wagner, T.L., Rykiel, E.J., Sharpe, P.J.H., Payne, T.L., Lin, S.K., 1985. Population dynamics of initiation and growth of southern pine beetle infestations. In: Branham, S.J., Thatcher, R.C. (Eds.), Proceedings of the Integrated Pest Management Symposium. In: USDA Forest Service General Technical Report SO-56, pp. 136-151.

Coulson, R.N., Flamm, R.O., Pulley, P.E., Payne, T.L., Rykiel, E.J., Wagner, T.L., 1986. Response of the southern pine bark beetle guild (Coleoptera: Scolytidae) to host disturbance. Environ. Entomol. 15, 850-858.

Coulson, R.N., McFadden, B.A., Pulley, P.E., Lovelady, C.N., Fitzgerald, J.W., Jack, S.B., 1999. Heterogeneity of forest landscapes and the distribution and abundance of the southern pine beetle. For. Ecol. Manag. 114, 471-485.

Cronin, J.T., Turchin, P., Hayes, J.L., Steiner, C.A., 1999. Area-wide efficacy of a localized forest pest management practice. Environ. Entomol. 28, 496-504.

Dahlsten, D.L., Six, D.L., Rowney, D.L., Lawson, A.B., Erbilgin, N., Raffa, K.F., 2004. Attraction of Ips pini (Coleoptera: Scolytinae) and its predators to natural attractants and synthetic semiochemicals in Northern California: implications for population monitoring. Environ. Entomol. 33, 1554-1561.

Davis, T.S., Hofstetter, R.W., 2009. Effects of gallery density and species ratio on the fitness and fecundity of two sympatric bark beetles (Coleoptera: Curculionidae). Environ. Entomol. 38, 639-650.

Dickens, J.C., 1979. Electrophysiological investigations of olfaction in bark beetles. Bull. Swiss Entomol. Soc. 52, 203-216.

Dickens, J.C., Payne, T.L., 1977. Bark beetle olfaction: pheromone receptor system in Dendroctonus frontalis. J. Insect Physiol. 23, 481-489.

Dickens, J.C., Billings, R.F., Payne, T.L., 1992. Green leaf volatiles interrupt aggregation pheromone response in bark beetles infesting southern pines. Experientia $48,523-524$.

Dixon, J.C., Osgood, E.A., 1961. Southern pine beetle: a review of present knowledge. USDA Forest Service Southern Forest Experiment Station Research Note S0-128, $34 \mathrm{pp}$. 
Dixon, W.N., Payne, T.L., 1979a. Aggregation of Thanasimus dubius on trees under massattack by the southern pine beetle. Environ. Entomol. 8, 178-181.

Dixon, W.N., Payne, T.L., 1979b. Attraction of entomophagous and associate insects of the southern pine beetle to beetle- and host tree-produced volatiles. J. Ga. Entomol. Soc. 15, 378-389.

Dixon, W.N., Payne, T.L., 1980. Sequence of arrival and spatial distribution of entomophagous and associate insects on southern pine beetle-infested trees. Texas Agricultural Experiment Station Bulletin Mp-1432, 27 pp.

Erbilgin, N., Raffa, K.F., 2000. Opposing effects of host monoterpenes on responses by two sympatric species of bark beetles to their aggregation pheromones. J. Chem. Ecol. 26, 2527-2548.

Erbilgin, N., Raffa, K.F., 2001. Modulation of predator attraction to pheromones of two prey species by stereochemistry of plant volatiles. Oecologia 127, 444-453.

Erbilgin, N., Powell, J.S., Raffa, K.F., 2003. Effect of varying monoterpene concentrations on the response of Ips pini (Coleoptera: Scolytidae) to its aggregation pheromone: implications for pest management and ecology of bark beetles. Agric. For. Entomol. 5, 269-274.

Erbilgin, N., Gillette, N.E., Mori, S.R., Stein, J.D., Owen, D.R., Wood, D.L., 2007a. Acetophenone as an anti-attractant for the western pine beetle, Dendroctonus brevicomis LeConte (Coleoptera: Scolytidae). J. Chem. Ecol. 33, 817-823.

Erbilgin, N., Krokene, P., Kvamme, T., Christiansen, E., 2007b. A host monoterpene influences Ips typographus (Coleoptera: Curculionidae, Scolytinae) responses to its aggregation pheromone. Agric. For. Entomol. 9, 135-140.

Erbilgin, N., Gillette, N.E., Owen, D.R., Mori, S.R., Nelson, A.S., Uzoh, F., Wood, D.L., 2008. Acetophenone superior to verbenone for reducing attraction of western pine beetle Dendroctonus brevicomis to its aggregation pheromone. Agric. For. Entomol. 10, 433-441.

Everaerts, C., Grégoire, J.C., Merlin, J., 2012. The toxicity of Norway spruce monoterpenes to two bark beetle species. In: Mattson, W.J., Levieux, J., Bernard-Dagan, C. (Eds.), Mechanisms of Woody Plant Defenses Against Insects: Search for Pattern. Springer, New York, pp. 335-344.

Fargo, W.S., Wagner, T.L., Coulson, R.N., 1985. Factors influencing the growth of multiple-tree infestations of Dendroctonus frontalis. Res. Popul. Ecol. 27, 25-38.

Fatzinger, C.W., 1985. Attraction of the black turpentine beetle (Coleoptera: Scolytidae) and other forest Coleoptera to turpentine-baited traps. Environ. Entomol. 14, 768-775.

Fatzinger, C.W., Siegfried, B.D., Wilkinson, R.C., Nation, J.L., 1987. trans-Verbenol, turpentine, and ethanol as trap baits for the black turpentine beetle, Dendroctonus terebrans, and other forest Coleoptera in North Florida. J. Entomol. Sci. 22, 201-209.

Fettig, C.J., Bulaon, B.M., Dabney, C.P., Hayes, C.J., McKelvey, S.R., 2012a. Verbenone Plus reduces levels of tree mortality attributed to mountain pine beetle infestations in whitebark pine, a tree species of concern. J. Biofert. Biopest 3, 123-128.

Fettig, C.J., McKelvey, S.R., Dabney, C.P., Huber, D.P., 2012b. Responses of Dendroctonus brevicomis (Coleoptera: Curculionidae) in behavioral assays: implications to development of a semiochemical-based tool for tree protection. J. Econ. Entomol. 105, 149-160.

Fettig, C.J., McKelvey, S.R., Dabney, C.P., Huber, D.P., Lait, C.G., Fowler, D.L., Borden, J.H., 2012c. Efficacy of "Verbenone Plus" for protecting ponderosa pine trees and stands from Dendroctonus brevicomis (Coleoptera: Curculionidae) attack in British Columbia and California. J. Econ. Entomol. 105, 1668-1680.

Flamm, R.O., Pulley, P.E., Coulson, R.N., 1993. Colonization of disturbed trees by the southern pine bark beetle guild (Coleoptera, Scolytidae). Environ. Entomol. 22, 62-70.

Flechtmann, C.A.H., Dalusky, M.J., Berisford, C.W., 1999. Bark and ambrosia beetle (Coleoptera: Scolytidae) responses to volatiles from aging loblolly pine billets. Environ. Entomol. 28, 638-648. 
Francke, W., Vité, J.P., 1983. Oxygenated terpenes in pheromone systems of bark beetles. Zeits. Angew. Entomol. 96, 146-156.

Franklin, R.T., 1970. Southern pine beetle population behavior. J. Georgia Entomol. Soc. 5, 175-182.

Fronk, W.D., 1947. The southern pine beetle-its life history. Virginia Agricultural Experiment Station Technical Bulletin, vol. 108. Blacksburg, VA, 12 pp.

Gara, R.I., 1967. Studies on the attack behavior of the southern pine beetle. I. The spreading and collapse of outbreaks. Contrib. Boyce Thompson Inst. 23, 349-354.

Gara, R.I., Coster, J.E., 1968. Studies on the attack behavior of the southern pine beetle. III. Sequence of tree infestation within stands. Contrib. Boyce Thompson Inst. 24, 77-85.

Gara, R.I., Vité, J.P., Cramer, H.H., 1965. Manipulation of Dendroctonus frontalis by use of a population aggregation pheromone. Contrib. Boyce Thompson Inst. 23, 55-66.

Gara, R.I., Geiszler, D.R., Litke, W.R., 1984. Primary attraction of the mountain pine beetle to lodgepole pine in Oregon. Ann. Entomol. Soc. Am. 77, 333-334.

Gries, G., Nolte, R., Sanders, W., 1989. Computer simulated host selection in Ips typographus. Entomol. Exp. Appl. 53, 211-217.

Gries, G., Leufvén, A., Lafontaine, J., Pierce, H., Borden, J., Vanderwel, D., Oehlschlager, A., 1990a. New metabolites of $\alpha$-pinene produced by the mountain pine beetle, Dendroctonus ponderosae (Coleoptera: Scolytidae). Insect Biochem. 20, 365-371.

Gries, G., Smirle, M.J., Leufven, A., Miller, D.R., Borden, J.H., Whitney, H.S., 1990b. Conversion of phenylalanine to toluene and 2-phenylethanol by the pine engraver Ips pini (Say) (Coleoptera, Scolytidae). Experientia 46, 329-331.

Grosman, D.M., 1996. Southern Pine Beetle, Dendroctonus frontalis Zimmermann (Coleoptera: Scolytidae): Quantitative Analysis of Chiral Semiochmicals, PhD Dissertation. Department of Entomology, Virginia Polytechnic Institute and State University, Blacksburg, Virginia, p.171.

Grosman, D.M., Salom, S.M., Ravlin, F.W., Young, R.W., 1997. Geographic and gender differences in semiochemicals in emerging adult southern pine beetle (Coleoptera: Scolytidae). Ann. Entomol. Soc. Am. 90, 438-446.

Hain, F.P., Duehl, A.J., Gardner, M.J., Payne, T.L., 2011. Natural history of the southern pine beetle. In: Coulson, R.N., Klepzig, K.D. (Eds.), Southern Pine Beetle II. In: General Technical Report SRS-140, USDA Forest Service Southern Research Station, Asheville, NC, pp. 13-24.

Harborne, J.B., 1988. Introduction to Ecological Biochemistry, third ed. Academic Press, London. 384 pp.

Hayes, J.L., Strom, B.L., Roton, L.M., Ingram, L.L., 1994. Repellent properties of the host compound 4-allylanisole to the southern pine beetle. J. Chem. Ecol. 20, 1595-1615.

Heikkenen, H.J., 1977. Southern pine beetle: a hypothesis regarding its primary attractant. J. Forestry 75, 412-413.

Hodges, J.D., Pickard, L.S., 1971. Lightning in the ecology of the southern pine beetle, Dendroctonus frontalis (Coleoptera: Scolytidae). Can. Entomol. 103, 44-51.

Hofstetter, R.W., Chen, Z., Gaylord, M.L., McMillin, J.D., Wagner, M.R., 2008. Synergistic effects of alpha-pinene and exo-brevicomin on pine bark beetles and associated insects in Arizona. J. Appl. Entomol. 132, 387-397.

Hofstetter, R.W., Gaylord, M.L., Martinson, S., Wagner, M.R., 2012. Attraction to monoterpenes and beetle-produced compounds by syntopic Ips and Dendroctonus bark beetles and their predators. Agric. For. Entomol. 14, 207-215.

Hopkins, A.D., 1909. Contributions toward a monograph of scolytid beeltes. I. Bark beetles of the genus Dendroctonus. U.S. Department of Agriculture, Bureau of Entomology Technical Series No. 17, Part 1, Washington, DC, 164 pp.

Hughes, P.R., 1973. Dendroctonus: production of pheromones and related compounds in response to host monoterpenes. Z. Angew. Entomol. 73, 294-312. 
Hughes, P.R., 1976. Response of female southern pine beetles to the aggregation pheromone frontalin. Z. Angew. Entomol. 81, 463-466.

Hughes, P.R., Renwick, J.A.A., Vité, J.P., 1976. The identification and field bioassay of chemical attractants in the roundheaded pine beetle. Environ. Entomol. 5, 1165-1168.

Hunt, D.W.A., Borden, J.H., 1990. Conversion of verbenols to verbenone by yeasts isolated from Dendroctonus ponderosae (Coleoptera: Scolytidae). J. Chem. Ecol. 16, 1385-1397.

Hunt, D.W.A., Borden, J.H., Lindgren, B.S., Gries, G., 1989. The role of autoxidation of alpha-pinene in the production of pheromones of Dendroctonus ponderosae (Coleoptera: Scolytidae). Can. J. For. Res. 19, 1275-1282.

Hynum, B.G., Berryman, A.A., 1980. Dendroctonus ponderosae (Coleoptera: Scolytidae): preaggregation landing and gallery initiation on lodgepole pine. Can. Entomol. 112, 185-191.

Johnson, P.C., Coster, J.E., 1978. Probability of attack by southern pine beetle in relation to distance from an attractive host tree. For. Sci. 24, 574-580.

Johnson, P.C., Coster, J.E., 1980. Seasonal and behavioral chemical effects on dispersion of the southern pine beetle within infestations. In: Berryman, A.A., Safranyik, L. (Eds.), Proceedings of the Second IUFRO Conference on Dispersal of Forest Insects: Evaluation, Theory and Management Implications, Washington State University, Pullman, WA, pp. 173-193.

Kinn, D.N., 1986. Studies on the flight capabilities of Dendroctonus frontalis and Ips calligraphus: preliminary findings using tethered beetles. USDA Forest Service, Southern Forest Experiment Station Res. Note SO-324, 3 pp.

Kinzer, G.W., Fentiman Jr., A.F., Page Jr., T.F., Foltz, R.L., Vité, J.P., 1969. Bark beetle attractants: identification, synthesis and field bioassay of a new compound isolated from Dendroctonus. Nature 221, 477-478.

Kohnle, U., Mussong, M., Dubbel, V., Francke, W., 1987. Acetophenone in the aggregation of the beech bark beetle, Taphrorychus bicolor (Col., Scolytidae). J. Appl. Entomol. 103, 249-252.

Lanier, G.N., Burkholder, W.E., 1974. Pheromones in speciation of Coleoptera. In: Birch, M.C. (Ed.), Pheromones. North-Holland Publishing, Amsterdam, pp. 161-189.

Lanier, G.N., Wood, D.L., 1975. Specificity of response to pheromones in the genus Ips (Coleoptera: Scolytidae). J. Chem. Ecol. 1, 9-23.

Lanier, G.N., Birch, M.C., Schmitz, R.F., Furniss, M.M., 1972. Pheromones of Ips pini (Coleoptera: Scolytidae): variation in response among three populations. Can. Entomol. 104, 1917-1923.

Lanier, G.N., Hendrichs, J.P., Flores, J.E., 1988. Biosystematics of the Dendroctonus frontalis (Coleoptera: Scolytidae) complex. Ann. Entomol. Soc. Am. 81, 403-418.

Latty, T.M., Reid, M., 2010. Who goes first? Condition and danger dependent pioneering in a group-living bark beetle (Dendroctonus ponderosae). Behav. Ecol. Sociobiol. 64, 639-646.

Lindgren, B.S., Miller, D.R., 2002. Effect of verbenone on five species of bark beetles (Coleoptera: Scolytidae) in lodgepole pine forests. Environ. Entomol. 31, 759-765.

Lovelady, C.N., Pulley, P.E., Coulson, R.N., Flamm, R.O., 1991. Relation of lightning to herbivory by the southern pine bark beetle guild (Coleoptera: Scolytidae). Environ. Entomol. 20, 1279-1284.

Macias-Samano, J., Borden, J., Gries, R., Pierce Jr., H., Gries, G., King, G., 1998. Primary attraction of the fir engraver, Scolytus ventralis. J. Chem. Ecol. 24, 1049-1075.

Martinson, S.J., Ylioja, T., Sullivan, B.T., Billings, R.F., Ayres, M.P., 2013. Alternate attractors in the population dynamics of a tree-killing bark beetle. Popul. Ecol. 55, 95-106.

McCarty, F.A., Billings, P.M., Richerson, J.V., Payne, T.L., Edson, L.J., 1980. Response of the southern pine beetle to behavioral chemicals in the laboratory. J. Ga. Entomol. Soc. $15,307-317$. 
Miller, M.C., 1983. Lightning Strike Simulation for Studying Southern Pine Bark and Engraver Beetle Attacks. USDA Forest Service, Southern Forest Experiment Station Research Note SO-296, 4 pp.

Miller, D.R., LaFontaine, J.P., 1991. cis-Verbenol: an aggregation pheromone for the mountain pine beetle Dendroctonus ponderosae (Coleoptera: Scolytidae). J. Entomol. Soc. Brit. Columb. 88, 34-38.

Miller, D.R., Rabaglia, R.J., 2009. Ethanol and (-)- $\alpha$-pinene: attractant kairomones for bark and ambrosia beetles in the southeastern US. J. Chem. Ecol. 35, 435-448.

Miller, D.R., Madden, J.L., Borden, J.H., 1986. Primary attraction of Ips latidens (LeConte) and Hylastes gracilis LeConte (Coleoptera, Scolytidae) to high-girdled lodgepole pine, Pinus contorta var latifolia Engelmann. Can. Entomol. 118, 85-88.

Miller, D.R., Borden, J.H., Slessor, K.N., 1989. Interpopulation and intrapopulation variation of the pheromone ipsdienol produced by male pine engravers, Ips pini (Say) (Coleoptera, Scolytidae). J. Chem. Ecol. 15, 233-247.

Mirov, N.T., 1961. Composition of gum turpentines of pines. USDA Forest Service Pacific Southwest Forest and Range Experiment Station Technical Bulletin 1239, Washington, DC, $158 \mathrm{pp}$.

Mizell, R.F.I., Frazier, J.L., Nebeker, T.E., 1984. Response of the clerid predator Thanasimus dubius (F.) to bark beetle pheromones and tree volatiles in a wind tunnel. J. Chem. Ecol. 10, 177-187.

Moeck, H.A., 1978. Field test for primary attraction of the spruce beetle. Canadian Forest Service Bi-monthly Research Note 34.8 pp.

Moeck, H.A., Simmons, C.S., 1991. Primary attraction of mountain pine beetle, Dendroctonus ponderosae Hopk. (Coleoptera: Scolytidae), to bolts of lodgepole pine. Can. Entomol. 123, 299-304.

Moeck, H.A., Wood, D.L., Lindahl Jr., K.Q., 1981. Host selection behavior of bark beetles (Coleoptera: Scolytidae) attacking Pinus ponderosa, with special emphasis on the western pine beetle, Dendroctonus brevicomis. J. Chem. Ecol. 7, 49-83.

Moore, G.E., 1972. Southern pine beetle mortality in North Carolina caused by parasites and predators. Environ. Entomol. 1, 58-65.

Moore, R.N., Golumbic, C., Fisher, G.S., 1956. Autoxidation of alpha-pinene. J. Am. Chem. Soc. 78, 1173-1176.

Moreno, B., Macías, J., Sullivan, B.T., Clarke, S.R., 2008. Field response of Dendroctonus frontalis (Coleoptera: Scolytinae) to synthetic semiochemicals in Chiapas. Mexico. J. Econ. Entomol. 101, 1821-1825.

Moser, J.C., 1987. Southern Pine Beetles Attack Felled Green Timber. USDA Forest Service, Southern Forest Experiment Station Res. Note SO-342, 8 pp.

Moser, J.C., Fitzgibbon, B.A., Klepzig, K.D., 2005. The mexican pine beetle, Dendroctonus mexicanus: first record in the United States and co-occurrence with the southern pine beetle-Dendroctonus frontalis (Coleoptera: Scolytidae or Curculionidae: Scolytinae). Entomol. News 116, 235-244.

Nebeker, T., 2011. Southern pine bark beetle guild. In: Coulson, R.N., Klepzig, K.D. (Eds.), Southern Pine Beetle II. In: General Technical Report SRS-140, USDA Forest Service Southern Research Station, Asheville, NC, pp. 199-209.

Niño-Domínguez, A., Sullivan, B.T., López-Urbina, J.H., Macías-Sámano, J., 2015a. Responses by Dendroctonus frontalis and Dendroctonus mesoamericanus (Coleoptera: Curculionidae) to semiochemical lures in Chiapas, Mexico: Possible roles of pheromones during joint host attacks. J. Econ. Entomol. 1-8. http://dx.doi.org/10.1093/jee/tov406, in press.

Niño-Domínguez, A., Sullivan, B.T., López-Urbina, J.H., Macías-Sámano, J.E., 2015b. Pheromone-mediated mate location and discrimination by two syntopic sibling species of Dendroctonus bark beetles in Chiapas. Mexico. J. Chem. Ecol. 41, 746-756. 
Økland, B., Skarpaas, O., Kausrud, K., 2009. Threshold facilitations of interacting species. Popul. Ecol. 51, 513-523.

Økland, B., Erbilgin, N., Skarpaas, O., Christiansen, E., Långström, B., 2011. Inter-species interactions and ecosystem effects of non-indigenous invasive and native tree-killing bark beetles. Biol. Invasions 13, 1151-1164.

Paine, T.D., Birch, M.C., Svihra, P., 1981. Niche breadth and resource patitioning by four sympatric species of bark beetles (Coleoptera: Scolytidae). Oecologia 48, 1-6.

Payne, T.L., 1975. Bark beetle olfaction. III. Antennal olfactory responsiveness of Dendroctonus frontalis Zimmerman and D. brevicomis Le Conte (Coleoptera: Scolytidae) to aggregation pheromones and host tree terpene hydrocarbons. J. Chem. Ecol. 1, 233-242.

Payne, T.L., 1980. Life history and habits. In: Thatcher, R.C., Searcy, J.L., Coster, J.E., Hertel, G.D. (Eds.), The Southern Pine Beetle, pp. 31-54. USDA Forest Service Science and Education Administration Technical Bulletin 1631.

Payne, T.L., 1986. Olfaction and vision in host finding by a bark beetle. In: Payne, T.L., Birch, M.C., Kennedy, C.E. (Eds.), Mechanisms in Insect Olfaction. Clarendon Press, Oxford, UK, pp. 111-116.

Payne, T.L., 1989. Olfactory basis for insect enemies of allied species. In: Kulhavy, D.L., Miller, M.C. (Eds.), Potential for Biological Control of Dendroctonus and Ips Bark Beetles. University of Texas Press, Austin, TX, pp. 55-69.

Payne, T.L., Billings, R.F., 1989. Evaluation of (S)-verbenone applications for suppressing southern pine beetle (Coleoptera: Scolytidae) infestations. J. Econ. Entomol. $82,1702-1708$.

Payne, T.L., Richerson, J.V., 1979. Management implications of inhibitors for Dendroctonus frontalis (Col. Scolytidae). Bull. Soc. Entomol. Suisse. 52, 323-331.

Payne, T.L., Richerson, J.V., 1985. Pheromone-mediated competitive replacement between two bark beetle populations: influence on infestation suppression. Z. Angew. Entomol. 99, 131-138.

Payne, T.L., Coster, J.E., Johnson, P.C., 1977. Effects of slow-release formulation of synthetic endo- and exo-brevicomin on southern pine beetle flight and landing behavior. J. Chem. Ecol. 3, 133-141.

Payne, T.L., Coster, J.E., Richerson, J.V., Edson, L.J., Hart, E.R., 1978a. Field response of the southern pine beetle to behavioral chemicals. Environ. Entomol. 7, 578-582.

Payne, T.L., Coster, J.E., Richerson, J.V., Hart, E.R., Hedden, R.L., Edson, L.J., 1978b. Reducing variation in field tests of behavioral chemicals for the southern pine beetle. J. Ga. Entomol. Soc. 13, 85-90.

Payne, T.L., Richerson, J.V., Dickens, J.C., West, J.R., Mori, K., Berisford, C.W., Hedden, R.L., Vité, J.P., Blum, M.S., 1982. Southern pine beetle: olfactory receptor and behavior discrimination of enantiomers of the attractant pheromone frontalin. J. Chem. Ecol. 8, 873-881.

Payne, T.L., Dickens, J.C., Richerson, J.V., 1984. Insect predator-prey coevolution via en antiomeric specificity in a kairomone-pheromone system. J. Chem. Ecol. 10, 487-492.

Payne, T.L., Kudon, L.H., Berisford, C.W., O’Donnel, B.P., Walsh, D.K., 1985a. Effects of frontalure in suppressing southern pine beetle spot growth under endemic and epidemic population levels. In: Branham, S.J., Thatcher, R.C. (Eds.), Integrated Pest Management Research Symposium: The Proceedings. In: General Technical Report SO-56. USDA Forest Service Southern Experiment Station, New Orleans, LA, pp. 281-287.

Payne, T.L., Kudon, L.H., Walsh, K.D., Berisford, C.W., 1985b. Influence of infestation density on suppression of $D$. frontalis infestations with attractant. Z. Angew. Entomol. 99, 39-43.

Payne, T.L., Billings, R.F., Delorme, J.D., Andryszak, N.A., Bartels, J., Francke, W., Vité, J.P., 1987. Kairomonal-pheromonal system in the black turpentine beetle, Dendroctonus terebrans (Ol.). J. Appl. Entomol. 103, 15-22. 
Payne, T.L., Andryszak, N.A., Wieser, H., Dixon, E.A., Ibrahim, N., Coers, J., 1988. Antennnal olfactory and behavioral response of southern pine beetle, Dendroctonus frontalis, to analogs of its aggregation pheromone frontalin. J. Chem. Ecol. $14,1217-1225$.

Payne, T.L., Billings, R.F., Berisford, C.W., Salom, S.M., Grosman, D.M., Dalusky, M.J., Upton, W.W., 1992. Disruption of Dendroctonus frontalis (Col., Scolytidae) infestations with an inhibitor pheromone. J. Appl. Entomol. 114, 341-347.

Phillips, T.W., Wilkening, A.J., Atkinson, T.H., Nation, J.L., Wilkinson, R.C., Foltz, J.L., 1988. Synergism of turpentine and ethanol as attractants for certain pine-infesting beetles (Coleoptera). Environ. Entomol. 17, 456-462.

Phillips, T.W., Nation, J.L., Wilkinson, R.C., Foltz, J.L., 1989. Secondary attraction and field activity of beetle-produced volatiles in Dendroctonus terebrans. J. Chem. Ecol. 15, 1513-1533.

Phillips, M.A., Savage, T.J., Croteau, R., 1999. Monoterpene synthases of loblolly pine (Pinus taeda) produce pinene isomers and enantiomers. Arch. Biochem. Biophys. 372, 197-204.

Pitman, G.B., Vité, J.P., 1969. Aggregation behavior of Dendroctonus ponderosae (Coleoptera: Scolytidae) in response to chemical messengers. Can. Entomol. 101, 143-149.

Pitman, G.B., Vité, J.P., Kinzer, G.W., Fentiman Jr., A.F., 1968. Bark beetle attractants: trans-verbenol isolated from Dendroctonus. Nature 218, 168-169.

Pitman, G.B., Vité, J.P., Kinzer, G.W., Fentiman Jr., A.F., 1969. Specificity of populationaggregating pheromones in Dendroctonus. J. Insect Physiol. 15, 363-366.

Plummer, E.L., Stewart, T.E., Byrne, K., Pearce, G.T., Silverstein, R.M., 1976. Determination of the enantiomeric composition of several insect pheromone alcohols. J. Chem. Ecol. 2, 307-331.

Powell, J., Tams, J., Bentz, B., Logan, J., 1998. Theoretical analysis of "switching" in a localized model for mountain pine beetle mass attack. J. Theor. Biol. 194, 49-63.

Pureswaran, D.S., Borden, J.H., 2004. New repellent semiochemicals for three species of Dendroctonus (Coleoptera: Scolytidae). Chemoecology 14, 67-75.

Pureswaran, D.S., Borden, J.H., 2005. Primary attraction and kairomonal host discrimination in three species of Dendroctonus (Coleoptera: Scolytidae). Agric. For. Entomol. 7, 219-230.

Pureswaran, D.S., Sullivan, B.T., 2012. Semiochemical emission from individual galleries of the southern pine beetle, (Coleoptera: Curculionidae: Scolytinae), attacking standing trees. J. Econ. Entomol. 105, 140-148.

Pureswaran, D.S., Gries, R., Borden, J.H., Pierce Jr., H.D., 2000. Dynamics of pheromone production and communication in the mountain pine beetle, Dendroctonus ponderosae Hopkins, and the pine engraver, Ips pini (Say) (Coleoptera: Scolytidae). Chemoecology 10, 153-168.

Pureswaran, D.S., Sullivan, B.T., Ayres, M.P., 2006. Fitness consequences of pheromone production and host selection strategies in a tree-killing bark beetle (Coleoptera: Curculionidae: Scolytinae). Oecologia 148, 720-728.

Pureswaran, D.S., Sullivan, B.T., Ayres, M.P., 2007. High individual variation in pheromone production by tree-killing bark beetles (Coleoptera: Curculionidae: Scolytinae). Naturwissenschaften 95, 33-44.

Pureswaran, D.S., Hofstetter, R.W., Sullivan, B.T., 2008a. Attraction of the southern pine beetle, Dendroctonus frontalis, to pheromone components of the western pine beetle, Dendroctonus brevicomis (Coleoptera:Curculionidae:Scolytinae), in an allopatric zone. Environ. Entomol. 37, 70-78.

Pureswaran, D.S., Sullivan, B.T., Ayres, M.P., 2008b. High individual variation in pheromone production by tree-killing bark beetles (Coleoptera:Curculionidae:Scolytinae). Naturwissenschaften 95, 33-44. 
Pye, J.M., Holmes, T.P., Prestemon, J.P., Wear, D.N., 2011. Economic impacts of the southern pine beetle. In: Southern Pine Beetle II. General Technical Report SRS-140, US Forest Service Southern Research Station, Asheville, NC, pp. 213-234.

Raffa, K.F., Berryman, A.A., 1980. Flight responses and host selection by bark beetles. In: Proceedings of the Second IUFRO Conference on Dispersal of Forest Insects: Evaluation, Theory, and Management Implications. Conference Office, Cooperative Extension Service, Washington State University, Pullman Washington, pp. 213-233.

Raffa, K.F., Dahlsten, D.L., 1995. Differential responses among natural enemies and prey to bark beetle pheromones. Oecologia 102, 17-23.

Raffa, K.F., Klepzig, K.D., 1989. Chiral escape of bark beetles from predators responding to a bark beetle pheromone. Oecologia 80, 566-569.

Raffa, K.F., Phillips, T.W., Salom, S.M., 1993. Strategies and mechanisms of host colonization by bark beetles. In: Schowalter, R.D., Filip, G.M. (Eds.), Beetle-Pathogen Interactions in Conifer Forests. Academic Press, London, pp. 103-128.

Redlich, H., Bruns, W., Francke, W., Schurig, V., Payne, T.L., Vité, J.P., 1987. Chiral building units from carbohydrates. XIII. Identification of the absolute configuration of endo-brevicomin from Dendroctonus frontalis and synthesis of both enantiomers from D-ribose. Tetrahedron 43, 2029-2034.

Reeve, J.D., 1997. Predation and bark beetle dynamics. Oecologia 112, 48-54.

Reeve, J.D., Strom, B.L., Rieske, L.K., Ayres, B.D., Costa, A., 2009. Geographic variation in prey preference in bark beetle predators. Ecol. Entomol. 34, 183-192.

Renwick, J.A.A., 1967. Identification of two oxygenated terpenes from the bark beetles Dendroctonus frontalis and Dendroctonus brevicomis. Contrib. Boyce Thompson Inst. 23, 355-360.

Renwick, J.A.A., 1970. Chemical aspects of bark beetle aggregation. Contrib. Boyce Thompson Inst. 24, 337-341.

Renwick, J.A.A., Hughes, P.R., 1975. Oxidation of unsaturated cyclic hydrocarbons by Dendroctonus frontalis. Insect Biochem. 5, 459-463.

Renwick, J.A.A., Vité, J.P., 1968. Isolation of the population aggregating pheromone of the southern pine beetle. Contrib. Boyce Thompson Inst. 24, 65-68.

Renwick, J.A.A., Vité, J.P., 1969. Bark beetle attractants: mechanism of colonization by Dendroctonus frontalis. Nature 224, 1222-1223.

Renwick, J.A.A., Vité, J.P., 1970. Systems of chemical communication in Dendroctonus. Contrib. Boyce Thompson Inst. 24, 283-292.

Renwick, J.A.A., Hughes, P.R., Ty, T.D., 1973. Oxidation products of pinene in the bark beetle Dendroctonus frontalis. J. Insect Physiol. 19, 1735-1740.

Renwick, J.A.A., Hughes, P.R., Vité, J.P., 1975. The aggregation pheromone system of a Dendroctonus bark beetle in Guatemala. J. Insect Physiol. 21, 1097-1100.

Renwick, J.A.A., Hughes, P.R., Pitman, G.B., Vité, J.P., 1976a. Oxidation products of terpenes identified from Dendroctonus and Ips bark beetles. J. Insect Physiol. 22, 725-727.

Renwick, J.A.A., Pitman, G.B., Vité, J.P., 1976b. 2-phenylethanol isolated from bark beetles. Naturwissenschaften 63, 198.

Richerson, J.V., Payne, T.L., 1979. Effects of bark beetle inhibitors on landing and attack behavior of the southern pine beetle and beetle associates. Environ. Entomol. $8,360-364$.

Richerson, J.V., McCarthy, F.A., Payne, T.L., 1980. Disruption of southern pine beetle infestations with frontalure. Environ. Entomol. 9, 90-93.

Rudinsky, J.A., 1973a. Multiple functions of the Douglas fir beetle pheromone 3-methyl-2-cyclohexen-1-one. Environ. Entomol. 2, 579-585.

Rudinsky, J.A., 1973b. Multiple functions of the southern pine beetle pheromone verbenone. Environ. Entomol. 2, 511-514. 
Rudinsky, J.A., Michael, R.R., 1974. Sound production in Scolytidae: 'rivalry' behaviour of male Dendroctonus beetles. J. Insect Physiol. 20, 1219-1230.

Rudinsky, J.A., Morgan, M.E., Libbey, L.M., Putnam, T.B., 1974. Antiaggregative-rivalry pheromone of the mountain pine beetle, and a new arrestant of the southern pine beetle. Environ. Entomol. 3, 90-97.

Ryker, L.C., 1988. Acoustic studies of Dendroctonus bark beetles. Fla. Entomol. 71, 447-461. Rykiel Jr., E.J., Coulson, R.N., Sharpe, P.J., Allen, T.F., Flamm, R.O., 1988. Disturbance propagation by bark beetles as an episodic landscape phenomenon. Landscape Ecol. 1, 129-139.

Saint-Germain, M., Buddle, C.M., Drapeau, P., 2007. Primary attraction and random landing in host-selection by wood-feeding insects: a matter of scale? Agric. For. Entomol. 9, 227-235.

Salom, S.M., Ascoli-Christensen, A., Birgersson, G., Payne, T.L., Berisford, C.W., 1992a. Electroantennogram responses of the southern pine beetle parasitoid Coeloides pissodis (Ashmead) (Hym., Braconidae) to potential semiochemicals. J. Appl. Entomol. 114, 472-479.

Salom, S.M., Billings, R.F., Upton, W.W., Dalusky, M.J., Grosman, D.M., Payne, T.L., Berisford, C.W., Shaver, T.N., 1992b. Effect of verbenone enantiomers and racemic endo-Brevicomin on response of Dendroctonus frontalis (Coleoptera, Scolytidae) to attractant-baited traps. Can. J. For. Res. 22, 925-931.

Salom, S.M., Grosman, D.M., McClellan, Q.C., Payne, T.L., 1995. Effect of an inhibitorbased suppression tactic on abundance and distribution of the southern pine beetle (Coleoptera: Scolytidae) and its natural enemies. J. Econ. Entomol. 88, 1703-1716.

Schlyter, F., Byers, J.A., Löfqvist, J., 1987a. Attraction to pheromone sources of different quantity, quality, and spacing: density-regulation mechanisms in bark beetle Ips typographus. J. Chem. Ecol. 13, 1503-1523.

Schlyter, F., Lofqvist, J., Byers, J.A., 1987b. Behavioural sequence in the attraction of the bark beetle Ips typographus to pheromone sources. Physiol. Entomol. 12, 185-196.

Schowalter, T., 2012. Ecology and management of bark beetles (Coleoptera: Curculionidae: Scolytinae) in southern pine forests. J. Integr. Pest Manage 3, 1-7.

Schowalter, T.D., Pope, D.N., Coulson, R.N., Fargo, W.S., 1981. Patterns of southern pine beetle (Dendroctonus frontalis Zimm.) infestation enlargement. For. Sci. 27, 837-849.

Seybold, S.J., 1993. Role of chirality in olfactory-directed behavior-aggregation of pine engraver beetles in the genus Ips (Coleoptera, Scolytidae). J. Chem. Ecol. 19, 1809-1831.

Seybold, S.J., Vanderwel, D., 2003. Biosynthesis and endocrine regulation of pheromone production in the Coleoptera. In: Blomquist, G.J., Vogt, R.G. (Eds.), Insect Pheromone Biochemistry and Molecular Biology. Elsevier Academic Press, London, pp. 137-200.

Seybold, S.J., Huber, D.P.W., Lee, J.C., Graves, A.D., Bohlmann, J., 2006. Pine monoterpenes and pine bark beetles: a marriage of convenience for defense and chemical communication. Phytochem. Rev. 5, 143-178.

Shepherd, W.P., Sullivan, B.T., 2013. Southern pine beetle, Dendroctonus frontalis, antennal and behavioral responses to nonhost leaf and bark volatiles. J. Chem. Ecol. 39, 481-493.

Siegfried, B.D., Fatzinger, C.W., Wilkinson, R.C., Nation, J.L., 1986. In-flight responses of the black turpentine beetle (Coleoptera: Scolytidae) to individual monoterpenes, turpentine, and paraquat-treated slash pines. Environ. Entomol. 15, 710-714.

Skillen, E.L., Berisford, C.W., Camaan, M.A., Reardon, R.C., 1997. Semiochemicals of Forest and Shade Tree Insects in North America and Management Applications. USDA Forest Service Forest Health Technology Enterprise Team Publication FHTET-96-15.

Smith, M.T., Payne, T.L., Birch, M.C., 1990. Olfactory-based behavioral interactions among five species in the southern pine bark beetle group. J. Chem. Ecol. 16, 3317-3331. 
Smith, M.T., Salom, S.M., Payne, T.L., 1993. The southern pine bark beetle guild: an historical review of the research on the semiochemical-based communication system of the five principal species. Va. Agric. Expt. Stn. Bull. 93-94, 106.

Staeben, J.C., Sullivan, B.T., Nowak, J.T., Gandhi, K.J., 2015. Enantiospecific responses of southern pine beetle (Dendroctonus frontalis) and its clerid predator, Thanasimus dubius, to $\alpha$-pinene. Chemoecology 25, 73-83.

Steidle, J.L., van Loon, J.J., 2002. Chemoecology of parasitoid and predator oviposition behaviour. In: Hilker, M., Meiners, T. (Eds.), Chemoecology of Insect Eggs and Egg Deposition. Blackwell, London, pp. 291-317.

Stephen, F.M., 2011. Southern pine beetle competitors. In: Coulson, R.N., Klepzig, K.D. (Eds.), Southern Pine Beetle II. In: General Technical Report SRS-140, USDA Forest Service Southern Research Station, Asheville, NC, pp. 183-198.

Stephen, F.M., Lih, M.P., 1985. A Dendroctonus frontalis infestation growth model: organization, refinement, and utilization. In: Branham, S.J., Thatcher, R.C. (Eds.), Proceedings, Integrated Pest Management Research Symposium. In: General Technical Report SO-56, USDA Forest Service Southern Forest Experiment Station, New Orleans. pp. 186-194.

Stewart, T.E., Plummer, E.L., McCanless, L.L., West, J.R., Silverstein, R.M., 1977. Determination of enantiomer composition of several bicyclic ketal insect pheromone components. J. Chem. Ecol. 3, 27-43.

Strom, B.L., Clarke, S.R., 2011. Use of semiochemicals for southern pine beetle infestation management and resource protection. In: Coulson, R.N., Klepzig, K.D. (Eds.), Southern Pine Beetle II. In: General Technical Report SRS-140, USDA Forest Service Southern Research Station, Asheville, NC, pp. 381-397.

Strom, B.L., Goyer, R.A., Hayes, J.L., 1995. Naturally occuring compound can protect pines from the southern pine beetle. Louisiana Agric. 38, 5-7.

Strom, B.L., Roton, L.M., Goyer, R.A., Meeker, J.R., 1999. Visual and semiochemical disruption of host finding in the southern pine beetle. Ecol. Appl. 9, 1028-1038.

Strom, B.L., Clarke, S.R., Shea, P.J., 2004. Efficacy of 4-allylanisole-based products for protecting individual loblolly pines from Dendroctonus frontalis Zimmermann (Coleoptera: Scolytidae). Can. J. For. Res. 34, 659-665.

Sullivan, B.T., 1997. The chemical ecology of host habitat location by larval parasitoids of the southern pine beetle, Dendroctonus frontalis Zimmermann: olfactory cues and their possible sources. PhD Thesis, Department of Entomology. University of Georgia, Athens, GA. p. 204.

Sullivan, B.T., 2005. Electrophysiological and behavioral responses of Dendroctonus frontalis (Coleoptera: Curculionidae) to volatiles isolated from conspecifics. J. Econ. Entomol. 98, 2067-2078.

Sullivan, B.T., Mori, K., 2009. Spatial displacement of release point can enhance activity of an attractant pheromone synergist of a bark beetle. J. Chem. Ecol. 35, 1222-1233.

Sullivan, B.T., Berisford, C.W., Dalusky, M.J., 1997. Field response of southern pine beetle parasitoids to some natural attractants. J. Chem. Ecol. 23, 837-856.

Sullivan, B.T., Pettersson, E.M., Seltmann, K.C., Berisford, C.W., 2000. Attraction of the bark beetle parasitoid Roptrocerus xylophagorum (Hymenoptera: Pteromalidae) to hostassociated olfactory cues. Environ. Entomol. 29, 1138-1151.

Sullivan, B.T., Dalusky, M.J., Wakarchuk, D., Berisford, C.W., 2007a. Field evaluations of potential aggregation inhibitors for the southern pine beetle, Dendroctonus frontalis (Coleoptera: Curculionidae). J. Entomol. Sci. 42, 139-149.

Sullivan, B.T., Shepherd, W.P., Pureswaran, D.S., Tashiro, T., Mori, K., 2007b. Evidence that $(+)$-endo-brevicomin is a male-produced component of the southern pine beetle aggregation pheromone. J. Chem. Ecol. 33, 1510-1527. 
Sullivan, B.T., Dalusky, M.J., Mori, K., Brownie, C., 2011. Variable responses by southern pine beetle, Dendroctonus frontalis Zimmermann, to the pheromone component endobrevicomin: influence of enantiomeric composition, release rate, and proximity to infestations. J. Chem. Ecol. 37, 403-411.

Sullivan, B.T., Niño, A., Moreno, B., Brownie, C., Macías-Sámano, J., Clarke, S.R., Kirkendall, L.R., Zúñiga, G., 2012. Biochemical evidence that Dendroctonus frontalis consists of two sibling species in Belize and Chiapas. Mexico. Ann. Entomol. Soc. Am. 105, 817-831.

Svihra, P., 1982. Influence of opposite sex on attraction produced by pioneer sex of four bark beetles species cohabiting pine in the southern United States. J. Chem. Ecol. 8, 373-378.

Svihra, P., Paine, T.D., Birch, M.C., 1980. Interspecific olfactory communications in southern pine beetles. Naturwissenschaften 67, 518-520.

Symonds, M.R.E., Elgar, M.A., 2004. Species overlap, speciation and the evolution of aggregation pheromones in bark beetles. Ecol. Lett. 7, 202-212.

Tchakerian, M.D., Coulson, R.N., 2011. Ecological impacts of southern pine beetle. In: Coulson, R.N., Klepzig, K.D. (Eds.), Southern Pine Beetle II. In: General Technical Report SRS-140, USDA Forest Service Southern Research Station, Asheville, NC, pp. 223-234.

Thatcher, R.C., 1960. Bark Beetles Affecting Southern Pines: A Review of Current Knowledge. USDA Forest Service Southern Forest Experiment Station Occ. Pap. 180, Pineville, LA, 25 pp.

Thatcher, R.C., Pickard, L.S., 1964. Seasonal variations in activity of the southern pine beetle in east Texas. J. Econ. Entomol. 57, 840-842.

Thatcher, R.C., Pickard, L.S., 1966. The clerid beetle, Thanasimus dubius, as a predator of the southern pine beetle. J. Econ. Entomol. 59, 955-957.

Turchin, P., Thoeny, W.T., 1993. Quantifying dispersal of southern pine beetles with markrecapture experiments and a diffusion model. Ecol. Appl. 3, 187-198.

Vet, L.E.M., Dicke, M., 1992. Ecology of infochemical use by natural enemies in a tritrophic context. Ann. Rev. Entomol. 37, 141-172.

Vité, J.P., 1970. Pest management systems using synthetic pheromones. Contrib. Boyce Thompson Inst. 24, 343-350.

Vité, J.P., Crozier, R.G., 1968. Studies on the attack behavior of the southern pine beetle. IV. Influence of host condition on aggregation pattern. Contrib. Boyce Thompson Inst. 24, 87-93.

Vité, J.P., Francke, W., 1976. The aggregation pheromones of bark beetles: progress and problems. Naturwissenschaften $63,550-555$.

Vité, J.P., Pitman, G.B., 1968. Bark beetle aggregation: effects of feeding on the release of pheromones in Dendroctonus and Ips. Nature 218, 169-170.

Vité, J.P., Renwick, J.A.A., 1968. Insect and host factors in the aggregation of the southern pine beetle. Contrib. Boyce Thomps. Inst. 24, 61-63.

Vité, J.P., Renwick, J.A.A., 1971. Inhibition of Dendroctonus frontalis response to frontalin by isomers of brevicomin. Naturwissenschaften 58, 418-419.

Vité, J.P., Williamson, D.L., 1970. Thanasimus dubius: prey perception. J. Insect Phys. 16, 233-239.

Vité, J.P., Bakke, A., Renwick, J.A.A., 1972. Pheromones in Ips (Coleoptera: Scolytidae): occurence and production. Can. Entomol. 104, 1967-1975.

Vité, J.P., Islas, S.F., Renwick, J.A.A., Hughes, P.R., Kliefoth, R.A., 1974. Biochemical and biological variation of southern pine beetle populations in North and Central America. Z. Angew. Entomol. 75, 422-435.

Vité, J.P., Hughes, P.R., Renwick, J.A.A., 1976. Southern pine beetle: effect of aerial pheromone saturation on orientation. Naturwissenschaften 63, 44. 
Vité, J.P., Billings, R.F., Ware, C.W., Mori, K., 1985. Southern pine beetle: enhancement or inhibition of aggregation response mediated by enantiomers of endo-brevicomin. Naturwissenschaften 72, 99-100.

Watterson, G.P., Payne, T.L., Richerson, J.V., 1982. The effects of verbenone and brevicomin on the within-tree populations of Dendroctonus frontalis. J. Ga. Entomol. Soc. $17,118-126$.

Werner, R.A., 1972. Aggregation behaviour of the beetle Ips grandicollis in response to hostproduced attractants. J. Insect Phys. 18, 423-437.

Witzgall, P., Kirsch, P., Cork, A., 2010. Sex pheromones and their impact on pest management. J. Chem. Ecol. 36, 80-100.

Wood, D.L., 1977. Manipulation of forest insect pests. In: Shorey, H.H., McKelvey, J.J. (Eds.), Chemical Control of Insect Behavior. John Wiley \& Sons, New York, pp. 369-384.

Wood, D.L., 1982a. The role of pheromones, kairomones, an allomones in the host selection and colonization behavior of bark beetles. Ann. Rev. Entomol. 27, 411-446.

Wood, S.L., 1982b. The bark and ambrosia beetles of North and Central America (Coleoptera: Scolytidae), a taxonomic monograph. Great Basin Nat. Mem. 6, 1359.

Wood, D.L., Bedard, W.D., 1977. The role of pheromones in the population dynamics of the western pine beetle. Proc. XV Int. Congr. Entomol. 15, 643-652.

Xu, L., Lou, Q., Cheng, C., Lu, M., Sun, J., 2015. Gut-associated bacteria of Dendroctonus valens and their involvement in verbenone production. Microb. Ecol. 70, 1012-1023.

Zhang, Q.H., Schlyter, F., 2003. Redundancy, synergism, and active inhibitory range of non-host volatiles in reducing pheromone attraction in European spruce bark beetle Ips typographus. Oikos 101, 299-310.

Zhang, Q.H., Schlyter, F., 2004. Olfactory recognition and behavioural avoidance of angiosperm nonhost volatiles by conifer-inhabiting bark beetles. Agric. For. Entomol. 6, 1-19.

Zhang, Q.H., Schlyter, F., Liu, G.T., Sheng, M.L., Birgersson, G., 2007. Electrophysiological and behavioral responses of Ips duplicatus to aggregation pheromone in inner mongolia, China: amitinol as a potential pheromone component. J. Chem. Ecol. 33, 1303-1315. 